\title{
Lightning morphology and impulse charge moment change of high peak current negative strokes
}

\author{
Gaopeng Lu, ${ }^{1}$ Steven A. Cummer, ${ }^{1}$ Richard J. Blakeslee, ${ }^{2}$ Stephanie Weiss, ${ }^{3}$ \\ and William H. Beasley ${ }^{3}$ \\ Received 20 September 2011; revised 28 December 2011; accepted 29 December 2011; published 28 February 2012.
}

[1] We have analyzed very high frequency lightning mapping observations and remote magnetic field measurements to investigate connections between lightning morphology and impulse charge moment change (iCMC) of negative cloud-to-ground (CG) strokes with high estimated peak currents. Four lightning morphologies are identified for a total of 2126 strokes within optimum detection range of the North Alabama Lightning Mapping Array, and statistical iCMC distributions are given for each of these types. Almost all $(>90 \%)$ of the largest impulse charge moments (greater than $-200 \mathrm{C} \mathrm{km}$ in this data set) are not produced by strokes in ordinary negative CG flashes. Instead, negative strokes with the largest iCMCs are almost exclusively associated with two unusual flash types that both initially develop as positive (normal) intracloud lightning. In the first type the negative stroke with high iCMCs results from a negative leader that descends from the midlevel negative charge region after the upper level negative leader ceases propagating. In the second type, the upper level negative leader of the intracloud lightning progresses toward ground as a so-called bolt from the blue to generate the negative stroke. Measurements of strokes associated with four negative polarity sprites suggest that all four were most likely produced in the first unusual lightning type. Our results highlight that estimated peak current and impulse charge transfer are not always well correlated and that the in-cloud lightning structure strongly influences charge transfer on short time scales in negative CG strokes.

Citation: Lu, G., S. A. Cummer, R. J. Blakeslee, S. Weiss, and W. H. Beasley (2012), Lightning morphology and impulse charge moment change of high peak current negative strokes, J. Geophys. Res., 117, D04212, doi:10.1029/2011JD016890.

\section{Introduction}

[2] Lightning peak current and charge transfer are key electrical properties of cloud-to-ground (CG) strokes. Rough estimates of peak current, subject to assumptions such as lightning channel geometry and return stroke speed [Willett et al., 1989; Rachidi et al., 2004], are routinely provided by several nationwide lightning detection systems. Careful studies indicate that these two quantities are highly correlated in rocket-triggered lightning on time scales of a few hundred microseconds after the return stroke, but this correlation drops with time indicating that the charge transfer at later time is not tightly linked to the return stroke peak current [Schoene et al., 2010]. A further implication is that the lightning peak current is not necessarily relevant to the total charge transfer shortly after return strokes, which can be

\footnotetext{
${ }^{1}$ Department of Electrical and Computer Engineering, Duke University, Durham, North Carolina, USA.

${ }^{2}$ Earth Science Office, NASA Marshall Space Flight Center, Huntsville, Alabama, USA. USA.

${ }^{3}$ School of Meteorology, University of Oklahoma, Norman, Oklahoma,

Copyright 2012 by the American Geophysical Union. 0148-0227/12/2011JD016890
}

evaluated with the impulse charge moment change (iCMC, defined empirically as the product of charge transferred from cloud to ground within $2 \mathrm{~ms}$ after the return stroke and its original height above the ground) [Cummer and Lyons, 2004, 2005]. In cases of positive strokes the impulse charge transfer occurs mainly along the in-cloud channels formed by prestroke negative leader progression $[\mathrm{Lu}$ et al., 2009], and the associated charge transportation is likely dependent on the status of lightning channels upon the occurrence of a return stroke. That the in-cloud lightning structure may be linked in an important way to lightning charge transfer, even on relatively short time scales of a few milliseconds, motivates several questions that are addressed in this work: how much variability is there in the impulse charge transfer of lightning strokes with comparable peak currents, and how is this variability connected to the incloud structure of lightning flashes?

[3] The primary goal of this work is to identify the characteristics of lightning morphology that are linked to the iCMC magnitude of negative strokes as determined from remote lightning magnetic fields. We focus exclusively on high peak current strokes in north Alabama detected by the National Lightning Detection Network (NLDN) [Cummins and Murphy, 2009], which limits the database size for 
study to reasonable levels that requires lightning classification by visually inspecting very high frequency (VHF) imaging data from the North Alabama Lightning Mapping Array (LMA) [Rison et al., 1999; Goodman et al., 2005]. Also, the few confirmed observations of negative polarity sprites, including three observed from a site near Duke University in 2008-2009 (reported in section 5.1) and four documented earlier [Barrington-Leigh et al., 1999; Taylor et al., 2008; Lyons, 2011], were all associated with lightning strokes with estimated peak currents higher than $-90 \mathrm{kA}$. This suggests that among negative CG strokes, those with relatively high peak currents are also much more prone to generate large impulse charge transfer whose origins are of our particular interest. Negative strokes with iCMCs capable of producing sprites are rarely documented [Williams et al., 2007], and the associated lightning structure remains unclear. The work presented here provides clues as to what kind of lightning morphology is likely conducive to negative sprites.

[4] We investigated the parent flashes of $\sim 2100$ negative strokes detected by NLDN as having peak currents higher than $-80 \mathrm{kA}$, a threshold that is slightly below the observed $-90 \mathrm{kA}$ cutoff peak current of negative sprite-producing strokes but that still yields a reasonably large database. The time-resolved spatial development of these flashes is examined with lightning mapping observations from the north Alabama LMA. It is found that high peak current negative strokes with the largest iCMCs (greater than $-200 \mathrm{C} \mathrm{km}$ in this data set) are almost exclusively produced by two abnormal lightning morphologies that are distinct from ordinary negative CG lightning. In the first type, the flash develops initially as positive polarity (normal) intracloud (IC) lightning and then produces negative CG strokes from the main negative cloud region. The second type is the socalled bolt-from-the-blue flash, in which the negative stroke results from the upper level leader progression as observed in positive IC lightning [Rison et al., 1999; Thomas et al., 2001]. Investigations on a statistical basis of the prestroke magnetic fields of negative strokes in different lightning types suggest that leaders in these abnormal flash types have similar magnitude of electrical current moment to those in ordinary negative CG flashes. This in turn suggests that it is the in-cloud lightning channels or charge regions that supply the charge for negative strokes with high iCMCs.

[5] Our findings suggest that negative sprites are likely associated with these two unusual lightning types, which partially explains the relative rarity of negative sprites [Williams et al., 2007]. Interestingly, measurements related to three negative sprites observed near Duke University and VHF mapping observations of a negative sprite within detection range of the Oklahoma LMA suggest that these four sprites were probably produced by the first unusual flash type (rather than by bolt-from-the-blue strokes), in which the sprite-producing negative stroke resulted from a negative leader descending from the main negative cloud region after long duration of negative leader progression in the upper part of the cloud.

[6] Collectively, we identify two major lightning morphologies producing large negative iCMCs, both of which are relatively uncommon in our database of negative strokes with high peak currents. Further, our results highlight that peak current and impulse charge transfer are not always well correlated for high peak current negative strokes, and that in-cloud lightning structure has a strong influence on the charge transfer on short time scales in lightning strokes.

\section{Data and Methods}

[7] Given the focus on negative strokes with high peak currents, our database is formed by 2126 lightning strokes with peak currents above $-80 \mathrm{kA}$ as located by NLDN within a $\sim 100 \times 100 \mathrm{~km}^{2}$ square region $\left(34.30-35.20^{\circ} \mathrm{N}\right.$, $\left.86.12-87.21^{\circ} \mathrm{W}\right)$ centered at the origin $\left(34.725^{\circ} \mathrm{N}, 86.645^{\circ} \mathrm{W}\right)$ of the north Alabama LMA. These strokes constitute less than $2 \%$ of the negative strokes detected by NLDN from 2004 through 2010 within the selected survey area. The north Alabama LMA is a ground-based multistation network that resolves the temporal lightning evolution in the threedimensional space by locating impulsive VHF (using the 76$82 \mathrm{MHz}$ frequency band) emissions in successive $100 \mu \mathrm{s}$ time windows [Goodman et al., 2005]. The basic morphology of lightning flashes associated with each negative stroke is determined by virtue of some well-known features shown by the VHF mapping observations [Shao et al., 1995; Shao and Krehbiel, 1996; Coleman et al., 2003, 2008]. Limiting the events to those relatively close (typically within $50 \mathrm{~km}$ in this work) to the center of the LMA network maximizes the chance to correctly identify the lightning morphology. At further distances, the sparsity of geolocated VHF sources can lead to ambiguous identification [Thomas et al., 2004].

[8] The LMA mapping results are usually interpreted on the basis of the bidirectional concept of lightning development, which depicts lightning as a plasma conduit that extends at its two ends of opposite polarities at the expense of electrostatic energy in thunderclouds [Kasemir, 1960; Mazur, 2002]. In the typical tripole charge structure of active thunderstorms [Williams, 1989], most of the LMA sources originate from negative leaders that pass through upper positively charged regions of the cloud (for positive IC discharges) or that extend toward ground after penetrating a lower positive charge region at the bottom of the cloud (for ordinary negative CG strokes); the rest mainly reflect intermittent recoil leaders (or $K$ process), also of negative polarity, that traverse the channels of previous positive leaders spreading in the midlevel main negative cloud region [Rison et al., 1999; Thomas et al., 2001; Mazur, 2002; Rust et al., 2005; Coleman et al., 2003, 2008; Lu et al., 2011b]. Our analyses indicate that the main negative cloud region of thunderstorms in north Alabama is typically centered at $6 \mathrm{~km}$ above mean sea level (msl), not significantly different from the orographic thunderstorms in central New Mexico where the ground level is about $1.8 \mathrm{~km} \mathrm{msl}$ [Rison et al., 1999]. The average elevation in area of the north Alabama LMA is approximately $200 \mathrm{~m}$.

[9] The iCMC of a lightning stroke is estimated from remote sensing of broadband lightning magnetic fields $[\mathrm{Hu}$ et al., 2002; Cummer and Lyons, 2004; Ross et al., 2008], which is dominated by the vertical component of a lightning current. Our analysis is primarily based on the measurements from a pair of orthogonal magnetic field sensors with approximate $3 \mathrm{~dB}$ bandwidth of $0.3 \mathrm{~Hz}$ to $500 \mathrm{~Hz}$. The magnetic signal is continuously recorded at $2.5 \mathrm{kHz}$ in Duke Forest $\left(35.970^{\circ} \mathrm{N}, 79.094^{\circ} \mathrm{W}\right)$ near Duke University, where the background noise is sufficiently low that the data are 


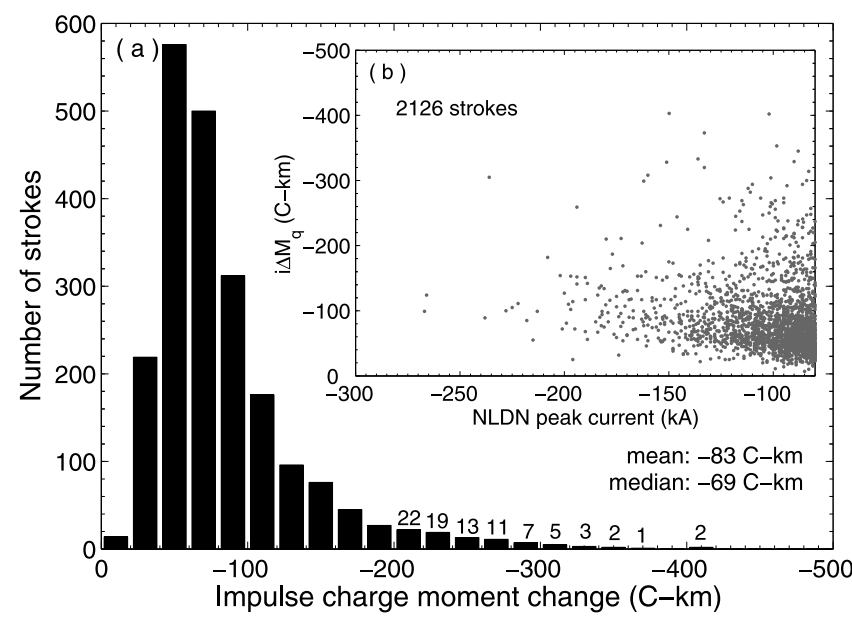

Figure 1. (a) Histogram of impulse charge moment changes (in $20 \mathrm{C} \mathrm{km}$ bins) of 2126 negative strokes detected by the National Lightning Detection Network (NLDN) with peak currents over $-80 \mathrm{kA}$ in a $100 \times 100 \mathrm{~km}^{2}$ area centered at the origin of the north Alabama lightning mapping array (LMA). (b) Scatterplot showing the peak current and impulse charge moment change $\left(i \Delta M_{q}\right)$ for individual strokes.

applicable to evaluate iCMCs as small as $\pm 3 \mathrm{C} \mathrm{km}$ at the distance $(\sim 750 \mathrm{~km})$ of the north Alabama LMA. A GPS clock provides the synchronization with NLDN and LMA measurements. Data acquisitions subject to system malfunctions or enhanced background noise from nearby lightning activity are not used in the analysis. The magnetic field of impulse charge transfer in lightning strokes usually appears as a pulse of $\sim 2 \mathrm{~ms}$ duration. In the cylindrical coordinates where the lightning stroke is placed at the origin, the remotely measured magnetic field dominated by the azimuthal component, $B_{\phi}(t)$, is the convolution result of lightning source current moment and the system impulse response, i.e.,

$$
B_{\phi}(t)=\int_{-\infty}^{\infty} M_{I}(\tau) h(t-\tau) \mathrm{d} \tau,
$$

where $M_{I}(t)$ is the time-resolved current moment (defined as the product of lightning current and its vertical channel length) of the stroke, and $h(t)$ describes the system impulse response that includes both the transfer function of lightning emissions in the Earth-ionosphere waveguide as computed from a 2-D finite difference time domain (FDTD) model [ $\mathrm{Hu}$ and Cummer, 2006] and the frequency response of magnetic sensors. With the known $B_{\phi}(t)$ and $h(t), M_{I}(t)$ can be solved with a deconvolution method introduced by Cummer and Inan [2000]. The impulse charge moment change (iCMC, or $\left.i \Delta M_{q}\right)$ is the time integral of the derived $M_{I}(t)$ over the first $2 \mathrm{~ms}$ after the lightning return stroke [Cummer, 2003], i.e.,

$$
i \Delta M_{q}=\int_{0}^{2} M_{I}(t) \mathrm{d} t
$$

where $t$ (ms) is the time after the inception of impulse charge transfer by the return stroke. A negative stroke that effectively transfers negative charge from cloud to ground generates a positive azimuthal magnetic field (that points counterclockwise) at the sensor, and yields a negative polarity iCMC. A small percentage ( $\sim 2 \%$ in our data set) of high peak current negative strokes reported by NLDN are actually fast discharging processes during the initial development of positive IC lightning that may produce positive iCMCs measurable at long range [ $\mathrm{Lu}$ et al., 2010, 2011a]; these events are not part of the analysis.

\section{Statistics of Impulse Charge Moments}

[10] Figure 1a shows the iCMC distribution for the 2126 negative strokes with high peak currents, exhibiting a smooth lognormal distribution with a long tail that approaches critical values of driving dielectric breakdown in the mesosphere in the form of red sprites [Pasko et al., 1997]. Although the exact threshold of sprite-producing iCMCs exhibits variability from night to night [Cummer and Lyons, 2005] and sprites can be produced by considerably lower positive iCMCs [Hu et al., 2002], limited measurements roughly indicate a threshold of $-500 \mathrm{C} \mathrm{km}$ for negative sprites [Williams et al., 2007]. The mean iCMC of our strokes is $-83 \mathrm{C} \mathrm{km}$, about twice the average $(-37 \mathrm{C} \mathrm{km})$ for 724 negative strokes with peak currents over $-10 \mathrm{kA}$ analyzed by Cummer and Lyons [2004] for a mesoscale convective system in the U.S. High Plains. The scatterplot in Figure $1 \mathrm{~b}$ indicates that, although impulse charge transfer generally increases for higher peak currents, there is a wide range of $\mathrm{iCMC}$ values for each peak current. This wide distribution may be in part a result of the dependence of peak current estimates on the speed of return strokes, which is highly variable and is not measured by lightning location systems [Rachidi et al., 2004]. The population of relatively high iCMCs greater than $-200 \mathrm{C} \mathrm{km}$ is almost present at all peak currents above $-80 \mathrm{kA}$, which emphasizes the significant variability in the impulse charge transfer of lightning strokes with comparably high peak currents.

[11] The largest iCMC in our data set, which is approximately $-400 \mathrm{C} \mathrm{km}$ produced in two strokes, remains short of driving sprites in the mesosphere given that the minimum iCMC reported in the literature for negative sprites was $-503 \mathrm{C} \mathrm{km}$ [Taylor et al., 2008]. Our observation is thus consistent with the rarity of negative sprites suggested by ground-based observations and the inferred rarity of high iCMC negative strokes in the continental United States [Cummer and Lyons, 2004]. We also note that the iCMC histogram in Figure 1a complies with the global survey of Williams et al. [2007] by measuring the Schumann resonance of lightning strokes. Their result of large negative charge moment changes for the North America section, with a substantially larger (by a factor of $\sim 120$ ) data set, also shows a lognormal distribution with a long tail extending to larger values with many sprite-producible charge moment changes.

\section{Impulse Charge Transfer With Different Lightning Morphology}

[12] We now fold varying lightning phenomenology into the analysis of impulse charge transfer produced by individual negative strokes with high peak currents. The 2126 

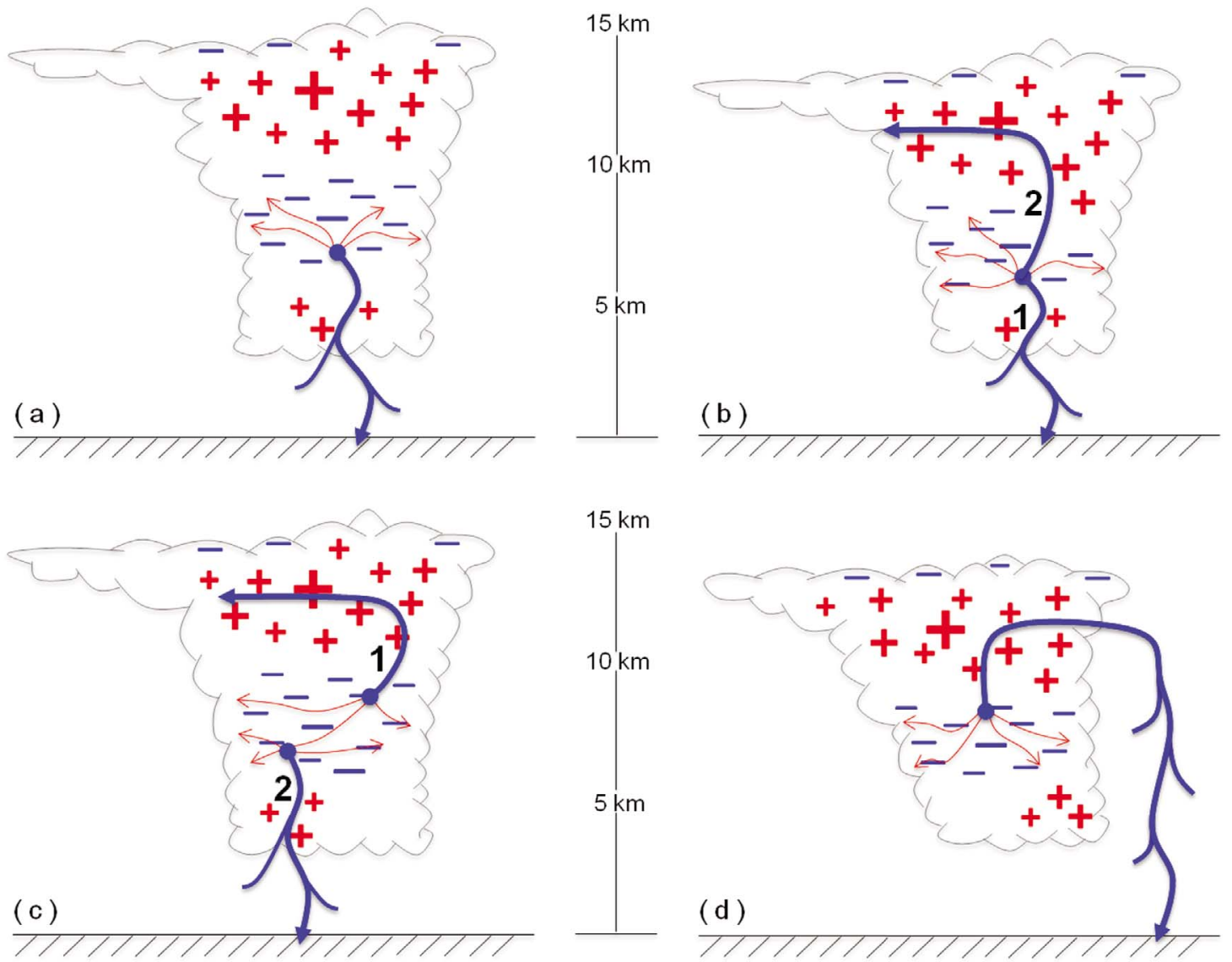

Figure 2. Schematic illustration of four lightning morphologies (in the context of normally electrified thunderclouds with a tripole charge structure) associated with high peak current negative cloud-to-ground (CG) strokes, including (a) ordinary negative CG lightning, (b) hybrid NCG-IC lightning, (c) hybrid IC-NCG lightning, and (d) bolt-from-the-blue lightning as described in Table 1. The progressions of negative and positive leaders are represented by thick blue and thin red lines, respectively. For lightning types (Figures $2 \mathrm{~b}$ and $2 \mathrm{c}$ ) that contain activity both in the lower and upper parts of the storm, the negative leader progression numbered 1 occurs first.

strokes selected for this study were produced in 2101 flashes, including 23 flashes that generated two high peak current strokes and one flash that had three. Although the sample size is relatively large, the development of these flashes falls into four distinct types of morphology as shown by VHF mapping observations. Figure 2 shows a sketch of these four lightning morphologies in the context of a tripole charge structure as possessed by normally electrified

Table 1. Four Different Lightning Morphologies in Association With High Peak Current Negative Strokes Within Optimum Detection Range of the North Alabama Lightning Mapping Array

\begin{tabular}{|c|c|c|}
\hline Lightning Morphology & Number of Strokes/Flashes ${ }^{a}$ & Flash Description \\
\hline $\begin{array}{l}\text { Ordinary negative cloud-to-ground } \\
\text { (NCG) flash }\end{array}$ & $1545 / 1528$ & $\begin{array}{l}\text { The flash, usually in a repetitive manner, develops downward negative } \\
\text { leaders from the midlevel negative cloud charge region and results } \\
\text { in discrete strokes (typically, } \geq 4 \text { ). }\end{array}$ \\
\hline Hybrid NCG-IC flash & $301 / 298$ & $\begin{array}{l}\text { The flash first produces discrete negative strokes (typically, 2-3) } \\
\text { following downward negative leaders and then develops an } \\
\text { upward negative leader into the upper positive cloud region. }\end{array}$ \\
\hline Hybrid IC-NCG flash & $232 / 227$ & $\begin{array}{l}\text { The flash begins as positive polarity intracloud lightning and then } \\
\text { generates discrete negative strokes (typically, } \leq 3 \text { ) associated } \\
\text { with downward negative leaders descending from the main } \\
\text { negative cloud region. }\end{array}$ \\
\hline Bolt-from-the-blue flash & $48 / 48$ & $\begin{array}{l}\text { The flash begins with an upward negative leader that propagates } \\
\text { horizontally and then turns downward toward ground to produce, } \\
\text { typically, one single stroke. }\end{array}$ \\
\hline
\end{tabular}

\footnotetext{
${ }^{\mathrm{a}}$ The number of negative strokes with peak currents higher than $-80 \mathrm{kA}$ and the number of parent flashes of these high peak current strokes (and other
} strokes with peak currents below $-80 \mathrm{kA}$ in the same flash). 

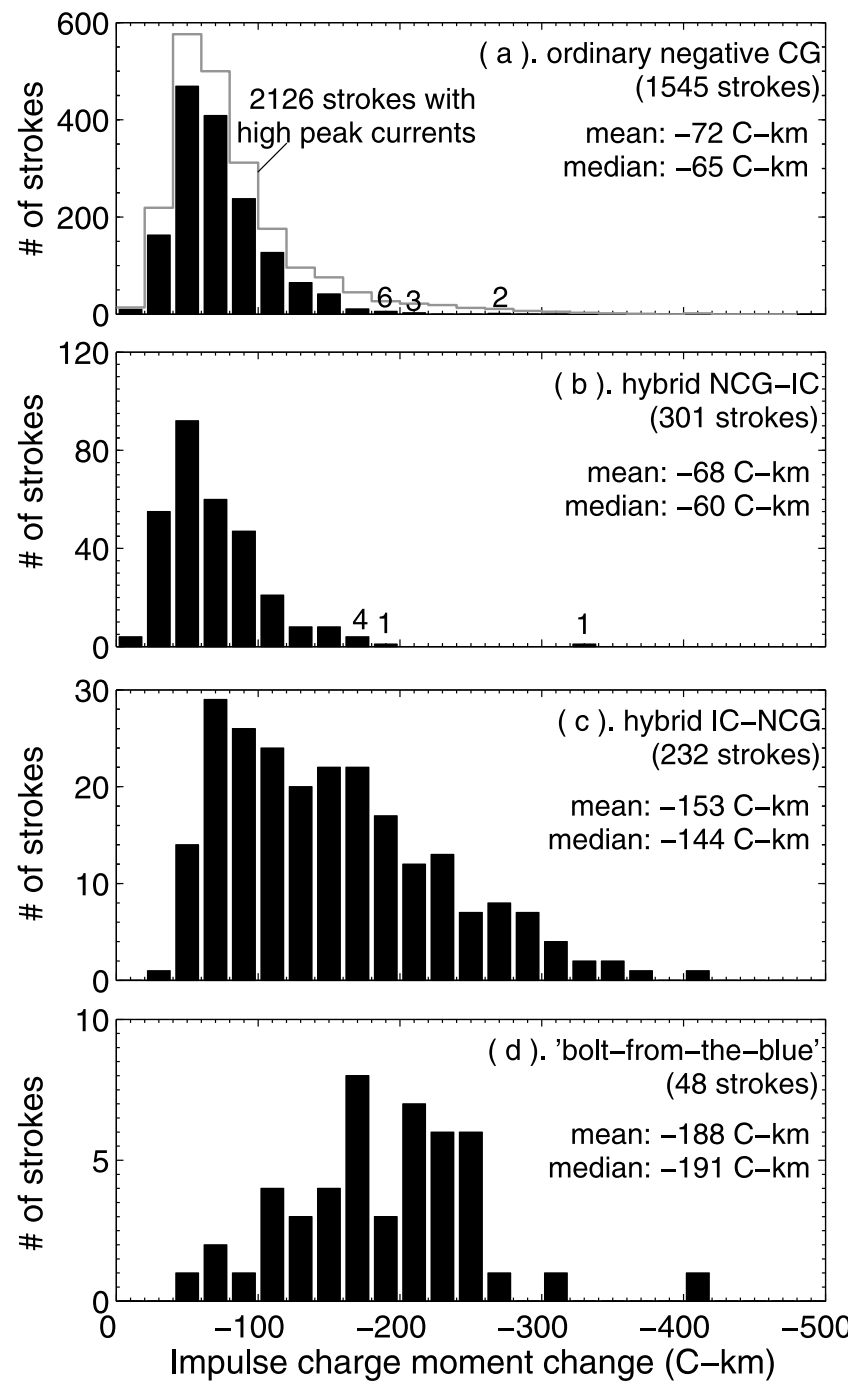

Figure 3. Histograms of impulse charge moment changes (in $20 \mathrm{C} \mathrm{km} \mathrm{bins)} \mathrm{of} \mathrm{(a)} \mathrm{lightning} \mathrm{strokes} \mathrm{in} \mathrm{ordinary} \mathrm{nega-}$ tive CG lightning, (b) strokes in hybrid NCG-IC lightning, (c) strokes in hybrid IC-NCG lightning, and (d) boltfrom-the-blue strokes, all having a peak current higher than $-80 \mathrm{kA}$ as estimated by NLDN.

thunderclouds [Williams, 1989; Krehbiel et al., 2008]. The progression of negative stepped leaders and positive leaders is indicated with thick blue and thin red lines, respectively. The phenomenological description and number of strokes and flashes of each type are given in Table 1. Note that the relative population of different lightning types and also the typical multiplicity are likely biased toward lightning flashes containing high peak current negative strokes that form our database.

[13] Most ( $73 \%$ ) negative strokes with high peak currents occur in ordinary CG flashes that typically develop a series of discrete terminations (called strokes) at the ground (Figure 2a). This lightning type has been the subject of extensive studies in the past [Clarence and Malan, 1957; Krehbiel et al., 1979; Beasley et al., 1982; Sonnenfeld et al., 2006; Coleman et al., 2008; Maggio et al., 2009] and here we report a variant that was also recently identified by Qie et al. [2005a] in their analysis of a thunderstorm on the Tibetan Plateau. The initial development of this abnormal lightning type (called hybrid NCG-IC flash) is the same as ordinary negative $\mathrm{CG}$, but its later progression is mainly in the upper part of the clouds as observed in positive IC lightning (Figure 2b). As shown in Figures $3 a$ and $3 b$, the statistical distributions of iCMCs associated with these two lightning types are similar. These two types together produce $\sim 87 \%$ of the high peak current strokes and dominate the lognormal distribution shown in Figure 1a without contributing significantly to the long tail beyond $-200 \mathrm{C} \mathrm{km}$, as shown by comparing with the iCMC histogram for the 2126 high peak current negative strokes (see Figure 3 a for ordinary negative $\mathrm{CG}$ ).

[14] Instead, the long tail in the iCMC histogram is primarily caused by the strokes that are preceded by long incloud activity as present in two unusual lightning types. Each of these two types produce many negative strokes with iCMCs in excess of $-200 \mathrm{C} \mathrm{km}$. Most of the impulse charge moments greater than $-200 \mathrm{C} \mathrm{km}$ are associated with an abnormal lightning type that we call the hybrid IC-NCG, which initially develops as positive IC lightning and then generates negative CG strokes (Figure 2c). The statistical iCMC distribution of high peak current strokes in this lightning type is plotted in Figure 3c. The other lightning type that produces many large iCMCs is the bolt-from-theblue flash (Figure 2d), which develops a substantial horizontal extension in the upper positive region of the cloud before it eventually descends toward ground to produce a negative CG stroke [Rison et al., 1999; Thomas et al., 2001]. As shown in Figure 3d, bolt-from-the-blue strokes tend to produce relatively large impulse charge transfer. The mean and median iCMC of these strokes are approximately $-190 \mathrm{C} \mathrm{km}$, slightly larger than that for hybrid IC-NCG lightning and almost three times that of strokes in ordinary negative CG and hybrid NCG-IC lightning.

[15] In the following we depict each of these lightning morphologies in detail with prototypical examples. For each of the flashes presented for a case study, we also include fast discharge processes detected by NLDN with peak currents over $10 \mathrm{kA}$ in the description of lightning development.

\subsection{Negative Strokes in Ordinary Negative CG Flashes}

[16] The majority $(\sim 73 \%)$ of negative strokes with high peak currents occur in ordinary CG flashes that discharge the midlevel negative cloud region through successive electrical connections with the ground (Figure 2a). The number of strokes in individual flashes is called the multiplicity of CG lightning [Rakov and Uman, 2003]. Charge transfer in ordinary CG flashes has been examined with ground-based multistation and balloon-borne electric field measurements [Brook et al., 1962; Krehbiel et al., 1979; Sonnenfeld et al., 2006; Hager et al., 2007; Maggio et al., 2009], and it is investigated here by combing VHF observations of flash evolution and remote sensing of lightning magnetic fields. Individual strokes of $\mathrm{CG}$ flashes that vary widely in peak current also exhibit large variability in the magnitude of impulse charge transfer. Our analyses are generally consistent with previous findings that first strokes usually have the highest peak current and transfer more charge than subsequent strokes in the same flash [Rakov and Uman, 1990]. It is also found that, however, as discussed later in this section, 

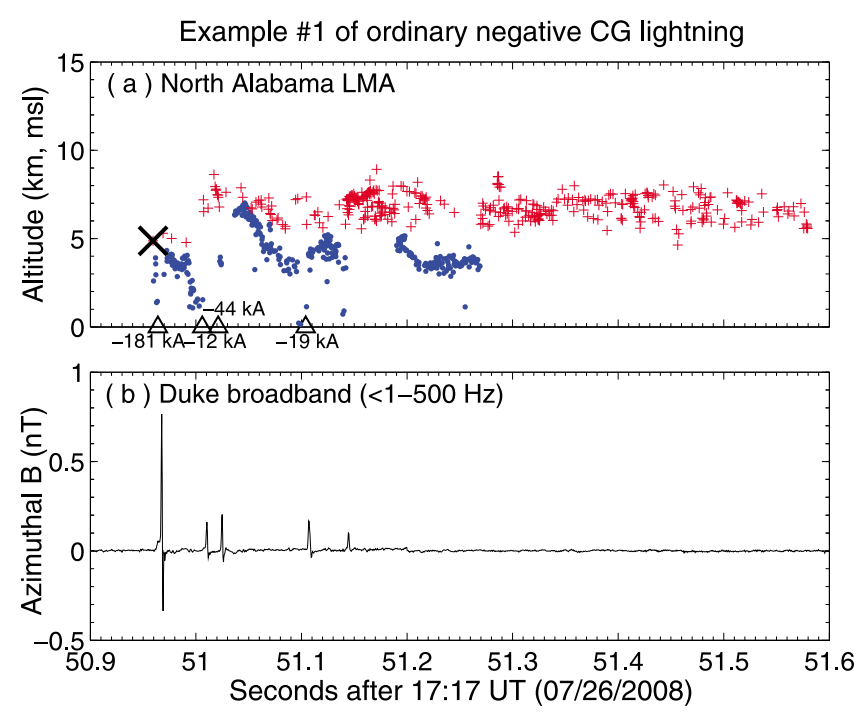

Figure 4. (a) Temporal variation in the altitude of VHF sources (blue dots for negative stepped leaders and red pluses for $K$ processes) detected by the north Alabama LMA for an ordinary negative CG flash that generated five ground strokes (indicated by triangles if detected by NLDN). The flash origin is indicated by a cross. (b) Broadband magnetic fields measured in Duke Forest showing the magnetic pulses caused by individual strokes.

subsequent strokes with high peak currents tend to produce larger iCMCs than first strokes with comparable peak currents.

[17] Figure 4 shows the measurements of a negative CG flash that generated five major strokes, each producing a positive magnetic pulse (indicative of negative charge transfer from cloud to ground). NLDN registered four of these strokes that are indicated by triangles in Figure 4a, where VHF sources that are most likely associated with negative stepped leaders and $K$ processes are discriminated with blue dots and red pluses, respectively. The first stroke, with a peak current of $-181 \mathrm{kA}$, occurred5 $\mathrm{ms}$ after the flash onset as inferred from the first VHF source (cross in Figure $4 \mathrm{a}$ ) at $\sim 5 \mathrm{~km}$ altitude (msl) and produced an $i \Delta M_{q}$ of $-134 \mathrm{C} \mathrm{km}$, which is larger than the summed iCMCs of all the subsequent strokes. The estimated average speed of the downward propagating negative leader is about $1 \times 10^{6} \mathrm{~m} / \mathrm{s}$, which is relatively high but remains reasonable by falling in the range of previous measurements [Beasley et al., 1982; Thomson et al., 1985; Rakov and Uman, 2003]. Previous analyses with ground-based multistation measurements of surface electric fields constrain the center of negative charge transferred by individual strokes in the main negative cloud region [Krehbiel et al., 1979], which for the flash plotted in Figure $4 \mathrm{a}$ is centered at $\sim 6.5 \mathrm{~km}(\mathrm{msl})$. Therefore, the first stroke transferred about $20 \mathrm{C}$ of negative charge to ground if all the charge was from the main negative region. The LMA mapping results adjoined with WSR-88D NEXRAD radar observations (not shown) from Huntsville, Alabama suggest that all these charges resided in a $5 \mathrm{~km} \times 5 \mathrm{~km}$ convective region of the cloud. The lightning activity after $51.15 \mathrm{~s}$ (absolute time after 17:17 UT) was dominated by $K$ processes between $5 \mathrm{~km}$ and $8 \mathrm{~km}$ altitude that spread out through the convective core and caused little variations in the Duke magnetic field. These $K$ processes also launched a negative leader (between $51.18 \mathrm{~s}$ and $51.27 \mathrm{~s}$ ) that descended to $3 \mathrm{~km}$ altitude (msl). That this leader did not result in a negative ground stroke indicates the presence of a relatively large positive charge region at the bottom of the cloud, which forms a potential well (for negative charge) that probably has prevented the negative stepped leader from reaching the ground [Coleman et al., 2003; Qie et al., 2005b; Nag and Rakov, 2009].

[18] Figure 5 shows the measurements of another ordinary negative CG flash with two high peak current negative strokes. Deflections in the magnetic field (Figure 5b) reflect the occurrence of seven negative strokes, five of which were reported by NLDN. The pilot stepped leaders preceding most of these strokes are visualized by the LMA mapping observations (Figure 5a). The first stroke, with a peak current of $-112 \mathrm{kA}$, caused a moderate $i \Delta M_{q}$ of $-50 \mathrm{C} \mathrm{km}$. In contrast, one subsequent stroke with a high peak current of $-106 \mathrm{kA}$ caused a much larger iCMC $(-273 \mathrm{C} \mathrm{km})$. The tacit negative leader progression prior to this stroke was not resolved by the LMA, indicative of a dart leader propagating along the path of a previous stroke that remained more or less conductive at the time of the high iCMC stroke.

[19] The iCMC histograms for first and subsequent strokes with high peak currents in ordinary negative $\mathrm{CG}$ flashes are plotted in Figures $6 \mathrm{a}$ and $6 \mathrm{~b}$, respectively. Although the iCMC distribution for subsequent strokes is not that smooth because of relatively few samples, it is noticed subsequent strokes tend to produce higher iCMCs than first strokes with comparable high peak currents. The mean and median iCMC ( -98 and $-93 \mathrm{C} \mathrm{km}$, respectively) of high peak current subsequent strokes are $\sim 45 \%$ larger than first strokes $(-68$
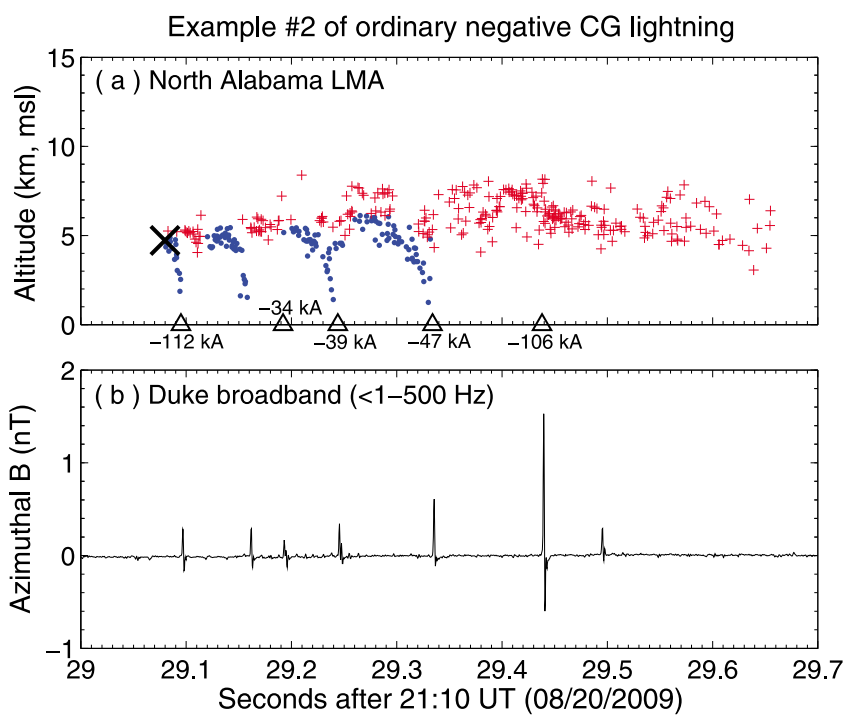

Figure 5. (a) Temporal variation in the altitude of VHF sources (blue dots for negative stepped leaders and red pluses for $K$ processes) detected by the north Alabama LMA for an ordinary negative CG flash that generated seven ground strokes (indicated by triangles if detected by NLDN). The flash origin is indicated by a cross. (b) Broadband magnetic fields measured in Duke Forest showing the magnetic pulses caused by individual strokes. 

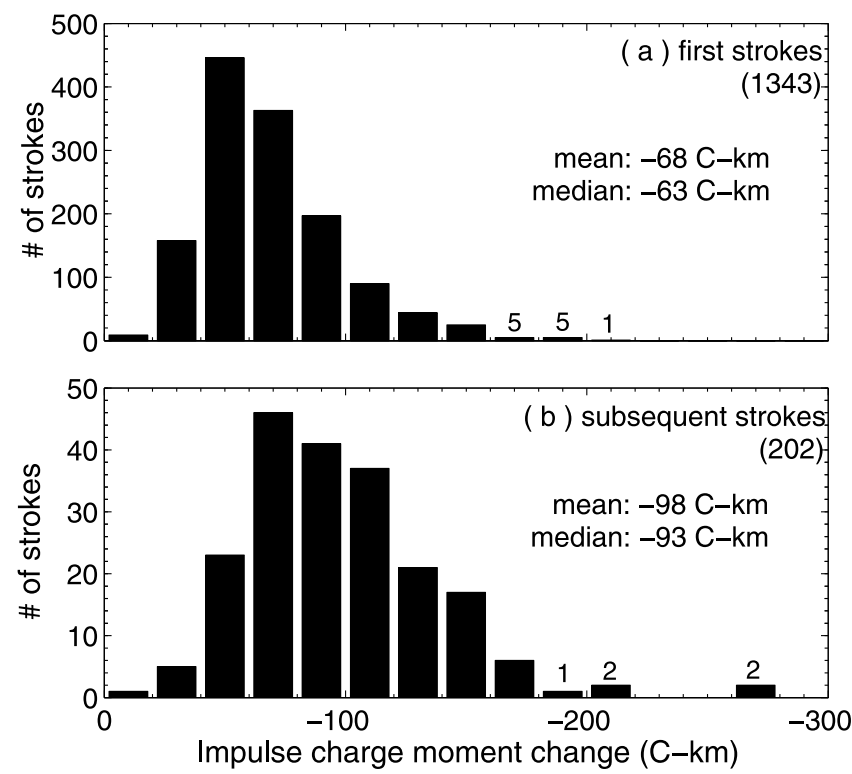

Figure 6. Statistical distribution of impulse charge moment changes (in $20 \mathrm{C} \mathrm{km}$ bins) of (a) the first stroke and (b) subsequent strokes with high peak currents in ordinary negative CG flashes.

and $-63 \mathrm{C} \mathrm{km}$, respectively). The largest iCMC $(-273 \mathrm{C} \mathrm{km})$ associated with ordinary negative CG lightning in our data set was caused by a subsequent stroke.

\subsection{Negatives Strokes in Hybrid NCG-IC Flashes}

[20] In this work we identified an unusual lightning type that initially evolves as ordinary CG lightning but later develops an upward negative leader into the upper part of the cloud (Figure 2b). Therefore, these flashes appear to transfer negative charge from the midlevel negative cloud region first to ground and then to the upper positive region. Similar lightning development was identified by Qie et al. [2005a] on the basis of coordinated high-speed camera observation and surface electric field measurements on the Tibetan Plateau. Here we term this abnormal flash type as hybrid NCGIC lightning which, unexpectedly, occurs not infrequently in north Alabama. About $14 \%$ of the high peak current strokes of our analysis occurred as first or subsequent strokes in hybrid NCG-IC flashes.

[21] Figure 7 shows the measurements for a hybrid NCGIC flash that produced its first stroke detected by NLDN with a peak current of $-94 \mathrm{kA}$. This stroke produced a relatively small $i \Delta M_{q}$ of $-44 \mathrm{C} \mathrm{km}$. NLDN also reported one of the two subsequent strokes that produced comparable iCMCs. The downward leader progression prior to each of the three strokes was clearly shown by the LMA observations. As shown in Figure 7a, the lightning development after the last ground stroke (not reported by NLDN) demonstrated a bilevel structure as usually observed in positive IC flashes [Rison et al., 1999; Thomas et al., 2001; Coleman et al., 2003]. The LMA points between $48.99 \mathrm{~s}$ and $49.02 \mathrm{~s}$ reflect a negatively charged leader that propagated upward at a mean vertical speed of $\sim 1.7 \times 10^{5} \mathrm{~m} / \mathrm{s}$. Right before and during the upward leader progression, there was no LMA point indicative of any considerable VHF radiation below $5 \mathrm{~km}$, which strongly suggests that this leader originated from the midlevel negative cloud region instead of being initiated by a positive ground stroke. In the observations of Qie et al. [2005a], the inferred absence of a ground connection during the upward negative leader progression of a hybrid NCG-IC flash was based on high-speed video images.

[22] Figure 8a shows the detailed spatial development of this flash by projecting the LMA sources to a vertical plane to the north of the flash. Figure $8 \mathrm{~b}$ shows the projection to a horizontal plane at sea level. These projections indicate that the upward negative leader initiated from close proximity (within $2 \mathrm{~km}$ ) of the cloud region discharged by previous negative strokes. Broadband magnetic fields plotted in Figure $7 \mathrm{~b}$ also indicate that the negative leader progression to $\sim 10 \mathrm{~km}$ altitude $(\mathrm{msl})$ gave rise to two negative magnetic pulses, each indicative of an $i \Delta M_{q}$ between +10 and $+20 \mathrm{C}$ $\mathrm{km}$. One of these pulses was associated with a fast discharging process detected by NLDN and classified correctly in this case as a $+12 \mathrm{kA}$ intracloud discharge (indicated by a diamond in Figure 7a). Similar magnetic pulses with larger amplitude can be produced by initial upward negative leaders in IC lightning associated with submillisecond bursts of energetic radiation (i.e., hard X-rays and gamma rays) observed by spaceborne and aircraft-borne detectors [ $\mathrm{Lu}$ et al., 2010, 2011a; Smith et al., 2011]. The upward negative leader turned horizontal and propagated for about $70 \mathrm{~ms}$; the rest of this flash was dominated by $K$ processes in the midlevel negative cloud region between 4 and $8 \mathrm{~km}$ (msl).
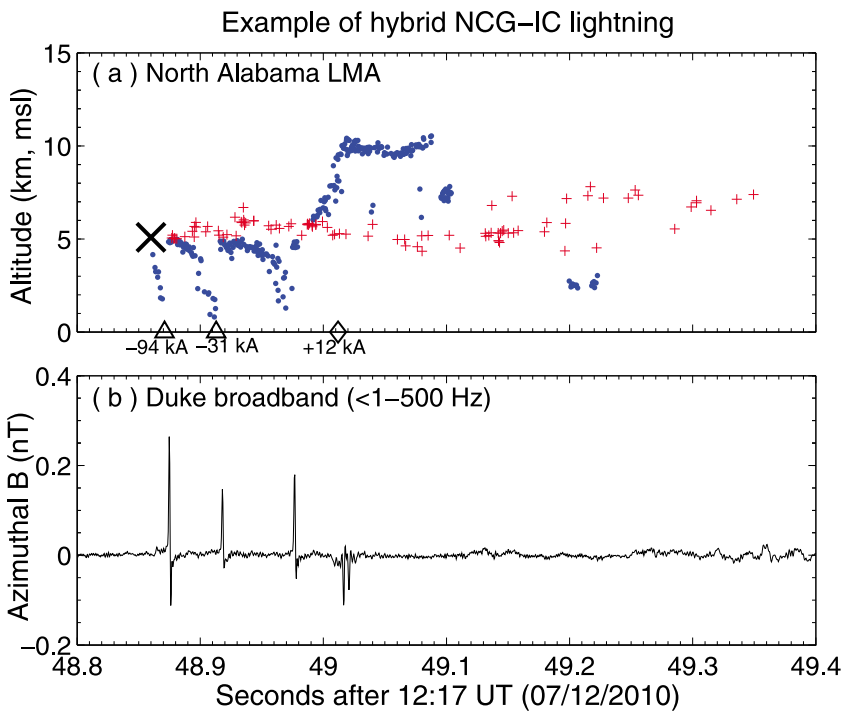

Figure 7. (a) Temporal variation in the altitude of VHF sources (blue dots for negative stepped leaders and red pluses for $K$ processes) detected by the north Alabama LMA during a hybrid NCG-IC flash that generated three negative strokes (indicated by triangles if detected by NLDN) and then developed upward into the upper positive cloud region. The flash origin is indicated by a cross, and the diamond indicates the occurrence of a NLDN-detected positive intracloud discharge during the upward negative leader progression. (b) Broadband magnetic fields measured in Duke Forest showing the deflections caused by individual negative strokes and also by the upward negative leader progression when it reached near $\sim 10 \mathrm{~km}(\mathrm{msl})$ altitude. 

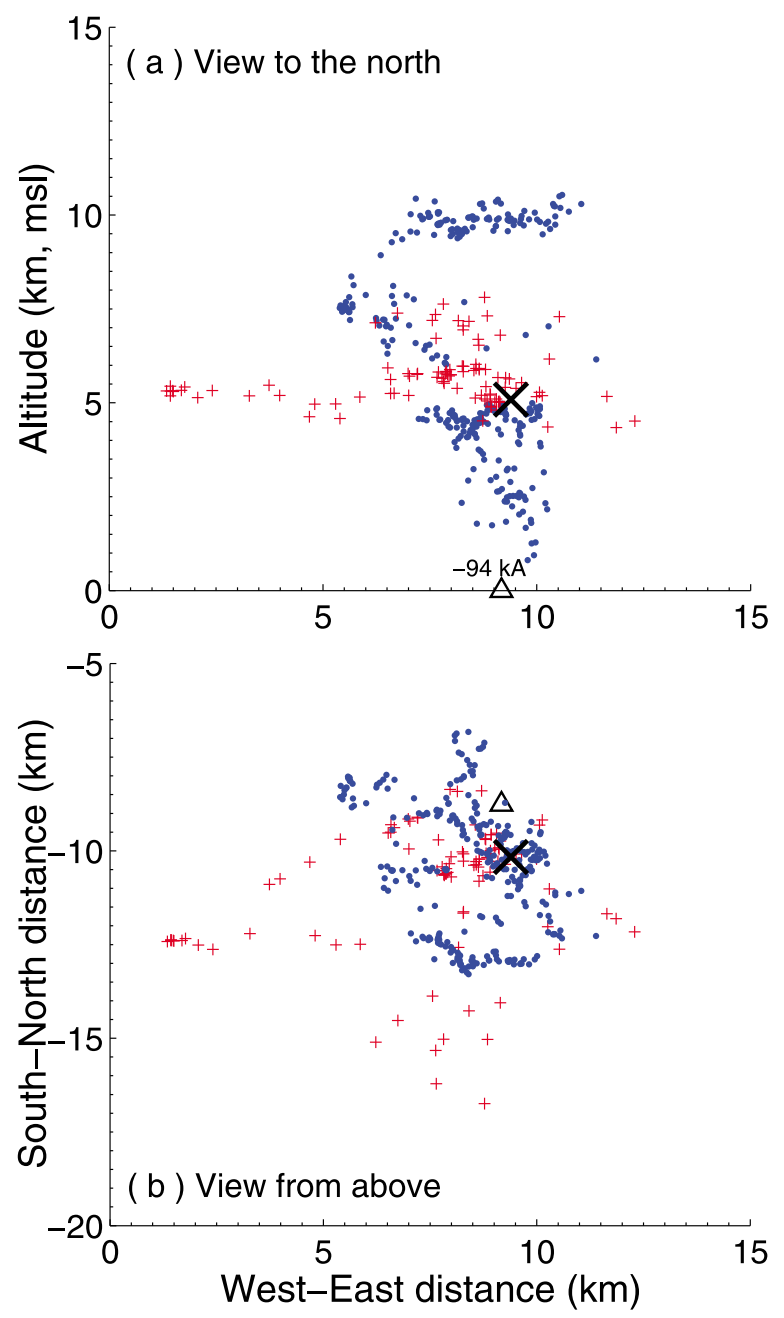

Figure 8. (a) Projection to a west-east vertical plane showing the spatial development of the hybrid NCG-IC flash in Figure 7a. (b) View from above showing the spatial development of the flash in the horizontal plane. In both plots the horizontal distance is relative to the LMA origin.

[23] For hybrid NCG-IC lightning, the statistical distribution of iCMCs for high peak current strokes peaks between -40 and $-60 \mathrm{C} \mathrm{km}$ (Figure $3 \mathrm{~b}$ ), and the mean and median iCMC of these strokes are -68 and $-60 \mathrm{C} \mathrm{km}$, respectively. Also, in hybrid NCG-IC lightning, subsequent strokes with high peak currents tend to produce higher (by $\sim 50 \%$ ) iCMCs than first strokes with comparable peak currents, and the maximum iCMC $(-329 \mathrm{C} \mathrm{km})$ is produced by a subsequent stroke. All of these aspects are remarkably similar to ordinary negative $\mathrm{CG}$ lightning. Therefore, the thunderstorm conditions in favor of hybrid NCG-IC do not have a pronounced effect on the impulse charge transfer of high peak current strokes. However, it remains interesting how a multistroke negative $\mathrm{CG}$ flash evolves subsequently as positive IC lightning. It has been known that a small lower positive charge region would favor negative $\mathrm{CG}$ lightning [Clarence and Malan, 1957; Pawar and Kamra, 2004]. Qie et al. [2005a] suggested that the IC part of hybrid NCG-IC lightning occurs when the positive charge region at lower altitudes becomes dissipated, for example, through the negative charge deposition by previous downward negative leaders [Shao et al., 1995]. Therefore, the NCG-IC transition might occur in the course of individual flashes in response to lightning-induced alternation in the thunderstorm charge structure, and the excess negative charge is consequently raised to the upper positive cloud region, instead of being lowered to ground. An observable effect of this form of charge transfer is that hybrid NCG-IC lightning usually produces fewer CG strokes (before the negative leader propagates into the upper positive region), or has a reduced multiplicity in comparison with ordinary negative $\mathrm{CG}$ flashes. The typical multiplicity of hybrid NCG-IC lightning is 2 to 3 , about half of ordinary negative $\mathrm{CG}$.

\subsection{Negative Strokes in Hybrid IC-NCG Flashes}

[24] In this section we discuss another hybrid flash type that begins as positive IC lightning and then produces one or more negative CG strokes (Figure 2c). This lightning morphology is also not infrequent $(\sim 11 \%)$ in north Alabama. We term this flash type as hybrid IC-NCG lightning, to be distinguished from hybrid NCG-IC lightning discussed in section 4.2. The iCMCs caused by high peak current strokes in this lightning type exhibit a broader distribution than ordinary negative CG strokes. As shown in Figure 9, hybrid IC-NCG lightning produced approximately two thirds of the high peak current strokes with iCMCs larger than $-200 \mathrm{C}$ $\mathrm{km}$ and is discussed in section 5 as the major flash type associated with negative sprites. The mean and median iCMC ( -153 and $-144 \mathrm{C} \mathrm{km}$, respectively) of hybrid ICNCG strokes are roughly twice that of ordinary negative strokes with comparable high peak currents.

[25] Figure 10 shows the measurements for a hybrid ICNCG flash that produced a high peak current $(-150 \mathrm{kA})$ negative stroke and several less intense strokes all located by NLDN within $1 \mathrm{~km}$ range. Only strokes with discernible magnetic deflections are indicated in Figure 10a. The $i \Delta M_{q}$

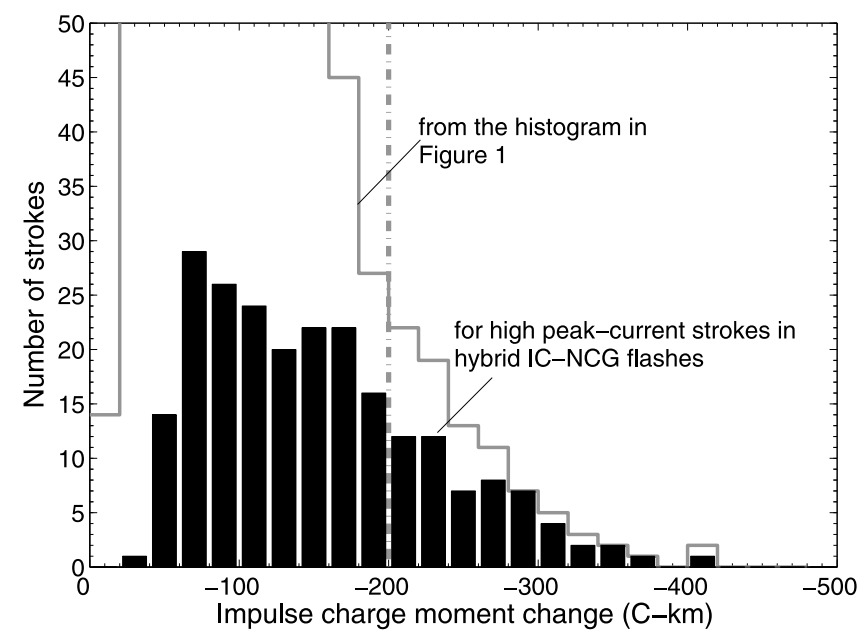

Figure 9. Statistical distribution of impulse charge moment changes (in $20 \mathrm{C} \mathrm{km}$ bins) of high peak current strokes in hybrid IC-NCG lightning. The histogram in Figure 1 is reproduced here to show that hybrid IC-NCG lightning is associated with most ( $\sim 65 \%$ ) of the largest impulse charge moment changes above $-200 \mathrm{C} \mathrm{km}$. 
Example of hybrid IC-NCG lightning
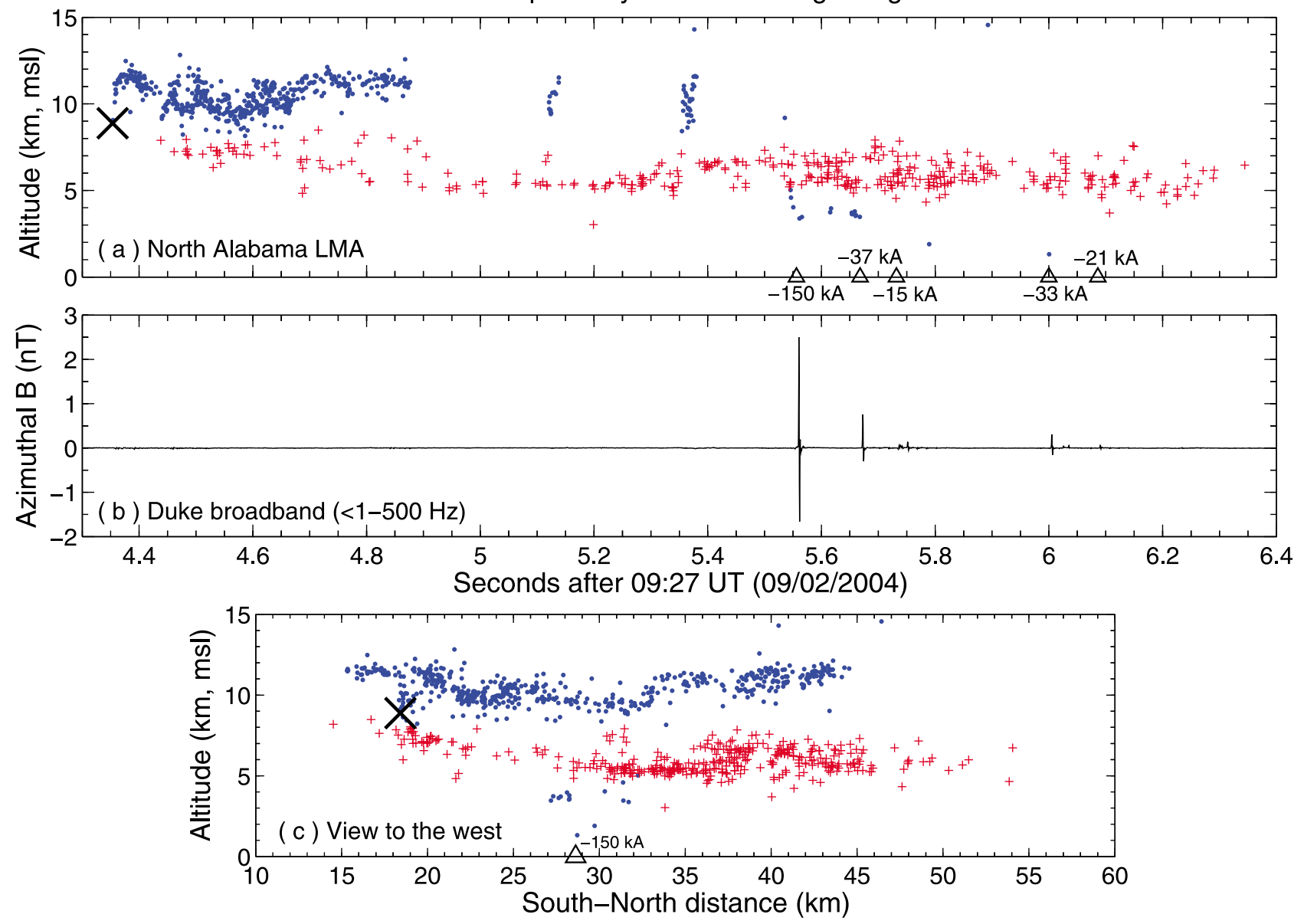

Figure 10. (a) Temporal variation in the altitude of VHF sources (blue dots for negative stepped leaders and red pluses for $K$ processes) detected by the north Alabama LMA during a hybrid IC-NCG flash that initially developed as bilevel intracloud lightning and then generated several negative strokes (indicated by triangles). The flash origin is indicated by a cross. (b) Broadband magnetic fields recorded in Duke Forest showing the slow magnetic pulses caused by individual strokes of the hybrid IC-NCG flash. (c) Projection to a south-north vertical plane showing the spatial development of the flash. The horizontal distance is relative to the LMA origin.

caused by this stroke is $-403 \mathrm{C} \mathrm{km}$, the largest of all the 2126 strokes we analyzed. As shown in Figure 10a, the lightning development before $4.9 \mathrm{~s}$ clearly shows the characteristic bilevel structure of a positive polarity IC flash between the two primary cloud charge regions centered at 6$7 \mathrm{~km}$ and above $10 \mathrm{~km}(\mathrm{msl})$, respectively [Coleman et al., 2003]. LMA sources associated with $K$ processes declined in altitude, indicating that positive leaders progressed deeper into the main negative cloud region. The lightning activity after $4.9 \mathrm{~s}$ was dominated by $K$ processes, some of which reactivated upward negative leaders and, surprisingly, also formed downward negative leaders to produce negative CG strokes. The spatial development of this flash, as shown in Figure 10c with LMA points projected onto a south-north vertical plane, indicates that the high peak current stroke occurred $\sim 10 \mathrm{~km}$ to the north of the flash origin. The comparison with NEXRAD radar observations shows that the stroke location was underneath the convective region of an air mass thunderstorm. Around the time of the first two CG strokes, there were also some LMA sources below $4 \mathrm{~km}$ (msl) and above the stroke location indicative of the propagation of negative leaders through a lower positive charge pocket near the bottom of the cloud. Therefore, the high peak current negative stroke might have resulted from intermittent $K$ processes associated with positive leaders that progressed above a localized lower positive charge region horizontally displaced from the flash origin. Negative breakdown associated with $K$ processes might form negative stepped leaders that pass through the lower positive charge region and result in negative $\mathrm{CG}$ strokes.

[26] In nearly all the hybrid IC-NCG flashes, negative CG strokes are produced when the upper level negative leader has stopped extending in the upper positive region (see the example in Figure 10a), which indicates that by that time the midlevel negative and the upper positive cloud region are not electrically connected through vertical lightning channels [Shao and Krehbiel, 1996]. We can thus further infer that the negative charge transferred to ground through these strokes is mainly from the main negative cloud region, instead of the negatively charged lightning channel lying in 

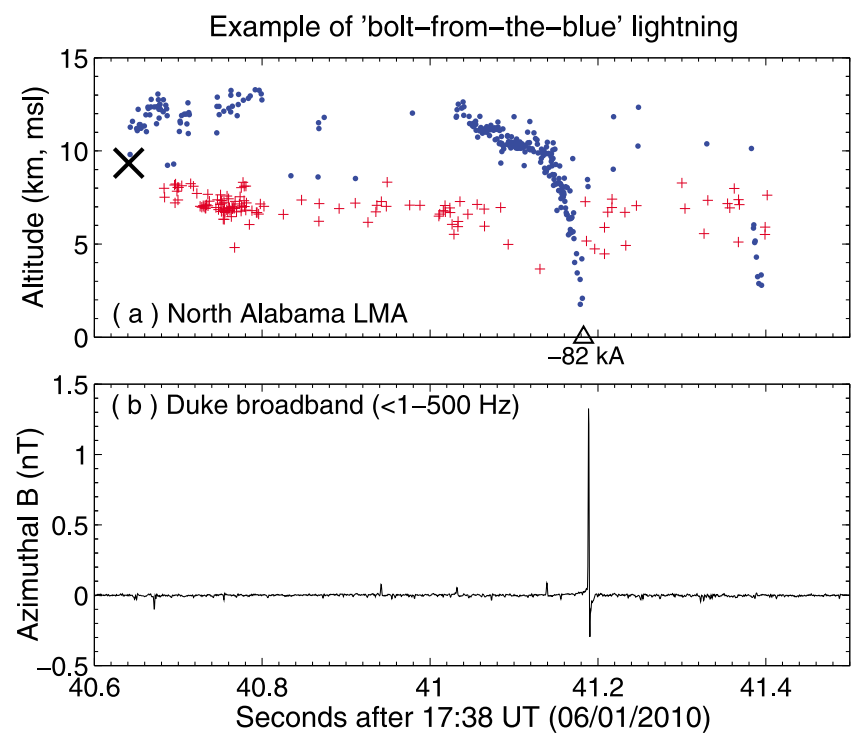

Figure 11. (a) Temporal variation in the altitude of VHF sources (blue dots for negative stepped leaders and red pluses for $K$ processes) detected by the north Alabama LMA in association with a bolt-from-the-blue (BFB) stroke (indicated by a triangle). The flash origin is indicated by a cross. (b) Broadband magnetic fields measured in Duke Forest showing the deflection caused by the bolt-from-theblue stroke.

the upper positive region. It is also noticed that hybrid ICNCG lightning produces fewer strokes (typically, $\leq 2$ ) than ordinary negative $\mathrm{CG}$, which seems expectable since a considerable fraction of negative charge residing in the main negative cloud region has been raised by previous negative leaders to the upper positive region [Maggio et al., 2009; Lu et al., 2011b]. On the other hand, it is worthwhile to understand why high peak current negative strokes occurring in this manner tend to transfer more charge (through impulse charge transfer) than ordinary negative strokes with comparable peak currents.

[27] It is possible that some hybrid IC-NCG lightning actually composes two separate flashes, one positive IC and one ordinary negative $C G$, that occur with considerable overlap in time from the same region of a thundercloud possessing a complicated charge structure. This is one case in which the classification of lightning morphology was not easy and that would be considered as hybrid IC-NCG in our analysis. If this situation also produces many large iCMCs, it would be equally interesting to answer the question as how the intracloud evolution plays a role in leading to high iCMC negative strokes in concurring CG flashes, for example, by altering the electrical potential distribution in thunderstorms.

[28] The hybrid IC-NCG lightning is similar in part of the spatial development to one of the typical lightning types that produce positive sprite-producing strokes. These flashes, also of hybrid type [Krehbiel, 1981], usually generate positive strokes underneath the trailing stratiform regions of summertime mesoscale convective systems and thus the stroke location is typically far from the flash origin typically in the convective regions [Boccippio et al., 1995; Lyons, 1996; Lu et al., 2009; Lang et al., 2010]. Interestingly, such lightning morphology also appears to have a small multiplicity (typically, $\leq 2$ ), although this is probably common to any types of positive CG flashes [Rakov and Uman, 2003].

\subsection{Negative Strokes in Bolt-From-the-Blue Flashes}

[29] Least (48 out of 2126 , or $\sim 2 \%$ ) of the negative strokes with high peak currents are produced by so-called bolt-from-the-blue lightning, which often propagates laterally out of clouds and strikes the ground at 10 to $20 \mathrm{~km}$ distances from the flash initiation region, appearing to descend from the clear sky (Figure 2d). The in-cloud spatial development of this lightning type is usually obscured by the cloud but can be inspected through LMA mapping observations, which show that bolt-from-the-blue lightning usually begins like an ordinary IC flash with the upper level negative leader emanating from the cloud and swerving toward ground [Rison et al., 1999; Thomas et al., 2001; Krehbiel et al., 2008].

[30] Figure 11 shows a bolt-from-the-blue flash that produced a single negative stroke with the return stroke current peaking at $-82 \mathrm{kA}$. This stroke produced a large $i \Delta M_{q}$ of $-248 \mathrm{C} \mathrm{km}$, roughly the typical values for the 48 high peak current bolt-from-the-blue strokes examined in this work. The spatial development of the flash is shown by the projection of LMA points to a west-east vertical plane (Figure 12). A cross marks the first LMA point and roughly represents the flash origin between the main negative and the upper positive charge regions. The initial negative leader initiated at about $9 \mathrm{~km}$ altitude, ascended to $13 \mathrm{~km}$ and then continued propagating horizontally for about $120 \mathrm{~ms}$. During the subsequent quiescence of about $220 \mathrm{~ms}$ in negative leader progression, $K$ processes remained active in the main negative cloud region and caused a resurrection of the upper level negative leader, which then progressed out of clouds and rushed toward ground at a mean velocity of $\sim 1.5 \times 10^{5} \mathrm{~m} / \mathrm{s}$. As indicated in Figure 12, the stroke location was about $13 \mathrm{~km}$ from the flash origin. The rest of this flash (after $41.2 \mathrm{~s}$ ) was dominated by $K$ processes in the main negative cloud region that might have caused

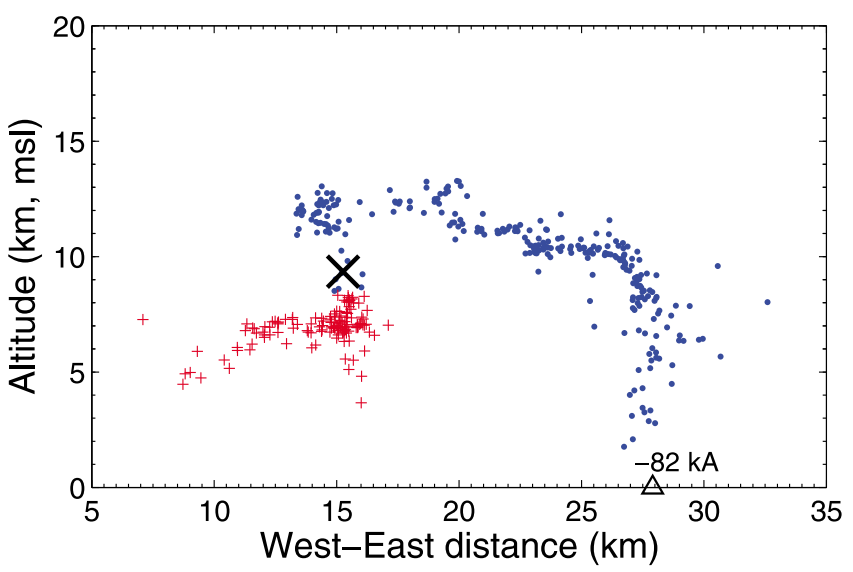

Figure 12. Projection of VHF sources to a west-east vertical plane showing the spatial development of the boltfrom-the-blue flash in Figure 11a. The flash origin and bolt-from-the-blue stroke location are indicated by a cross and triangle, respectively. The horizontal distance is relative to the LMA origin. 
additional leader progression along previous lightning channels but did not generate another ground stroke.

[31] The occurrence of bolt-from-the-blue lightning is thought to reflect a depleted upper positive charge region relative to the midlevel negative region of the cloud, forming a charge imbalance in the upper part of thunderclouds [Krehbiel et al., 2008]. This charge imbalance can be a consequence of the convection-driven mixing of the upper positive charge with the uppermost negative screening layer [Riousset et al., 2010]. High peak current strokes in about half of the bolt-from-the-blue flashes result directly from the initial upward negative leader, which implies that this charge imbalance may already exist before the occurrence of boltfrom-the-blue strokes. In the other half cases, the bolt-fromthe-blue stroke is either associated with a rejuvenation of the upper level negative channel (see Figure 11a), or associated with a newly formed upward negative leader that progresses horizontally in a different direction. This indicates that the initial leader activity might also often play a role in dissipating the upper positive charge to form or exaggerate the charge imbalance. The similar process may occur to make conditions more favorable for negative lightning leaders to escape from the cloud top, forming negative gigantic jets that propagate upward to the lower base of the ionosphere [Krehbiel et al., 2008; Lu et al., 2011c].

[32] In comparison with ordinary negative strokes with comparable high peak currents, bolt-from-the-blue strokes are typically preceded by a relatively long leader progression at the horizontal level above $10 \mathrm{~km}(\mathrm{msl})$. The negative charge distributed along the leader channel is transferred to ground during the ensuing return stroke [Krehbiel et al., 1979]. As it is not feasible for us to estimate the line charge density along the lightning channel, we cannot tell if the negative leader channel is the major source of the impulse charge transfer. For the bolt-from-the-blue lightning in Figure 12, if the negative charge removal by the impulse charge transfer is uniformly distributed along the leader channel, we compute a line charge density to be about $-0.7 \mathrm{mC} / \mathrm{m}$. This value is not particularly large or small compared to previous measurements of charge density of lightning channels ranging from 0.02 to $32 \mathrm{mC} / \mathrm{m}$ [Proctor, 1997; Thomson et al., 1985; Liu and Krehbiel, 1985; Warner et al., 2003; Lu et al., 2011b; Winn et al., 2011]. Therefore, it remains unclear whether and by how much the main negative charge region is discharged through the impulse charge transfer (within $2 \mathrm{~ms}$ after the return stroke) in a bolt-from-the-blue stroke. This question needs to be investigated with complementary ground-based or balloon-borne measurements of lightning-induced electric field changes at sufficiently close distances from the lightning source, which have been applied to locate the actual charge source tapped by individual strokes in ordinary negative CG flashes [Krehbiel et al., 1979; Sonnenfeld et al., 2006].

\section{Implications for Negative Sprite-Producing Strokes}

[33] In section 4 we presented four different lightning morphologies that are observed to produce negative $\mathrm{CG}$ strokes with high peak currents. The vast majority $(\sim 87 \%)$ of these strokes are produced in ordinary negative CG flashes and a close variant that develops a poststroke progression into the upper positive charge region. Because these two lightning types do not exhibit pronounced difference in the production of impulse charge moments, in the following analysis lightning strokes associated with both types are called ordinary negative strokes. Despite of the apparent dominance in occurrence rate, these strokes are least potent in producing the largest iCMCs. For instance, only six (out of 1846 strokes, or $<0.4 \%$ ) ordinary negative strokes produced an impulse charge transfer greater than $-200 \mathrm{C} \mathrm{km}$, most occurring as subsequent strokes in the flash. It should be mentioned that for ordinary negative $\mathrm{CG}$ flashes examined with one or more high peak current strokes, we have also evaluated other strokes with peak currents below $-80 \mathrm{kA}$, and did not find strokes with iCMCs greater than $-200 \mathrm{C} \mathrm{km}$.

[34] By contrast, a considerably large fraction ( $25 \%)$ of IC-NCG strokes with high peak currents produced large iCMCs in excess of $-200 \mathrm{C} \mathrm{km}$ (Figure 3c). As discussed in section 4.3, hybrid IC-NCG strokes dominate the long tail in Figure 1 toward the nominal threshold $(-500 \mathrm{C} \mathrm{km})$ of negative sprite initiation and, very likely, also make the major contribution to the longer tail extending beyond $-500 \mathrm{C} \mathrm{km}$ in Figure 1 of Williams et al. [2007]. The lack of a negative iCMC larger than this critical value in our data set is probably caused by a relatively small data set and intrinsic dynamics/intensity of thunderstorms in north Alabama, and warrants further exploration of sprite-producing negative strokes in a larger area around the north Alabama LMA and in regions with a much richer population of high peak current negative strokes.

[35] Bolt-from-the-blue strokes with high peak currents are a subsidiary candidate that might yield large iCMCs capable of producing sprites. About half of the bolt-fromthe-blue strokes produce large iCMCs greater than $-200 \mathrm{C}$ $\mathrm{km}$. However, bolt-from-the-blue flashes are probably not the major lightning type conducive to negative sprites, which is true at least in north Alabama in light of the statistical significance of associated iCMCs close to the critical values for producing negative sprites.

[36] Therefore, vigorous negative strokes that produce sprites are most likely produced in hybrid IC-NCG or bolt-from-the-blue flashes, both of which are unusual lightning types that experience a significant negative leader progression in the upper part of the storm before generating the negative stroke(s). However, our data set does not contain any strokes with iCMCs exceeding the critical value for triggering sprites, and hence we cannot preclude the possibility that the actual sprite-producing strokes occur with an exotic lightning morphology different from those identified in this work. It is therefore necessary to evaluate our conjecture with observations relevant to negative sprites. Here we present the measurements of three negative sprites observed from Duke Forest and one near the Oklahoma LMA. The analyses of these events consistently indicate that sprite-producing negative strokes produce iCMCs in excess of $-500 \mathrm{C} \mathrm{km}$, and the associated return stroke peak currents are higher than $-90 \mathrm{kA}$. 

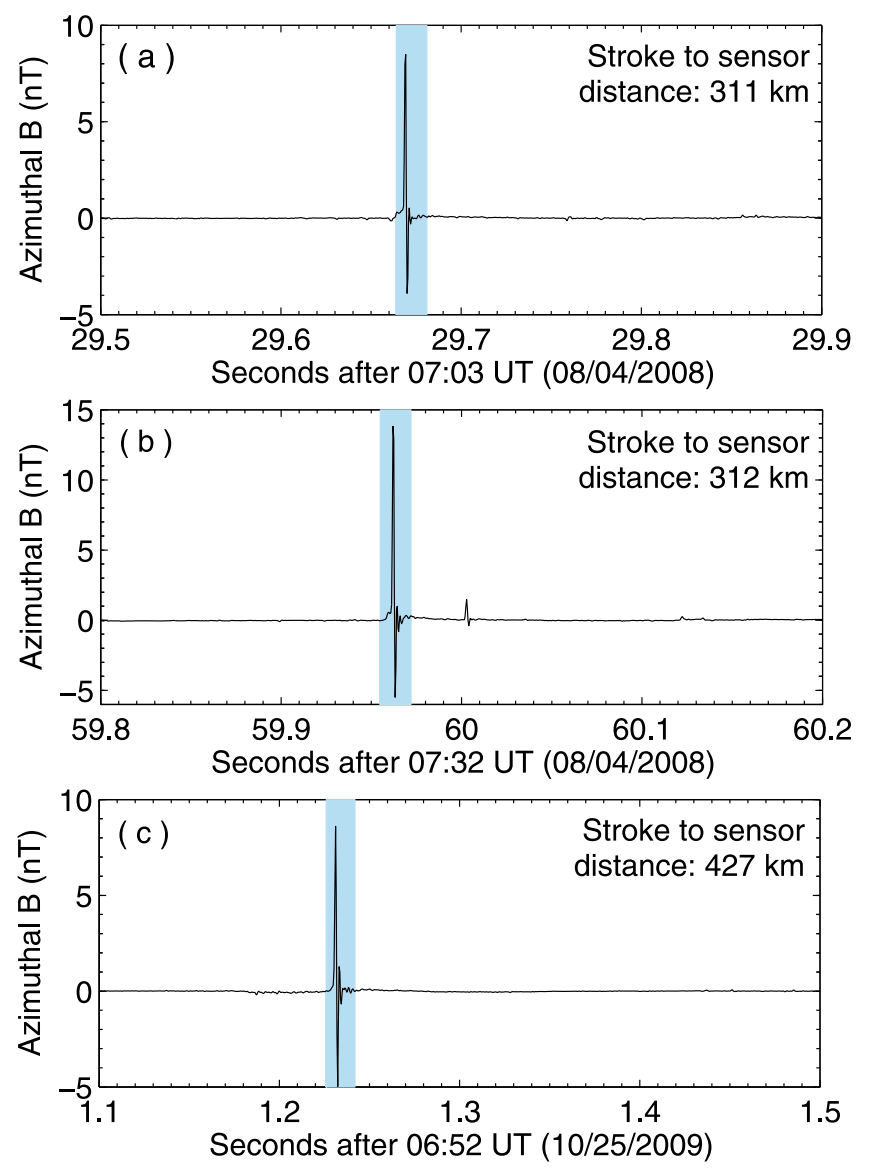

Figure 13. Broadband $(<1-500 \mathrm{~Hz})$ magnetic fields of three negative CG strokes that produced sprites observed from Duke Forest. The sprite associated with each stroke is visible in the shaded time interval (17 ms duration); in other words, each of these strokes produced the sprite within 17 $\mathrm{ms}$ after the return stroke that occurred at the onset of the impulse charge transfer.

\subsection{Measurements of Negative Sprites}

[37] A ground-based low light level video camera has been installed in Duke Forest to monitor transient luminous events near the eastern coast of the United States. The GPS time is stamped to individual video fields with $\sim 17 \mathrm{~ms}$ resolution. Out of numerous sprites since first observations early in 2008 , only three were confirmed to be related to negative strokes that were all registered by NLDN with peak currents higher than $-100 \mathrm{kA}$. The magnetic fields of these sprite-producing strokes measured in Duke Forest are plotted in Figure 13, where the shaded area marks the time interval over which the sprite was visible in the video fields. Two of these negative sprites were observed about $30 \mathrm{~min}-$ utes apart over an isolated air mass storm in South Carolina on 4 August 2008. The third negative sprite observed on 25 October 2009 was associated with an oceanic thunderstorm about $120 \mathrm{~km}$ from the coastline. Comparisons with NEXRAD radar observations from Wilmington, North Carolina indicate that all of these sprite-producing negative strokes were located underneath the cloud regions with deep convection.
[38] It is apparent that the parent flashes of these negative sprites generated a first stroke that either dominated over subsequent strokes (Figure 13b) or exhibited distinct loneliness (Figures 13a and 13c), and there is no sign of exotic lightning activity. The distinction of negative strokes that produced sprites, as indicated by the magnetic recordings over the presumed duration $(\sim 2 \mathrm{~s})$ of the parent lightning (not fully shown in Figure 13), is consistent with our observations of the major negative stroke in hybrid IC-NCG and bolt-from-the-blue lightning. As discussed in section 4, the multiplicity of these two lightning types is typically $\leq 3$, and the first stroke usually dominates in peak current and impulse charge transfer. In contrast, ordinary negative CG flashes typically generate four or more strokes that often exhibit little dominance of a first stroke. In the data set we analyzed, all the six ordinary high peak current negative strokes with iCMCs greater than $-200 \mathrm{C} \mathrm{km}$ are produced by flashes with relatively large multiplicity $(\geq 4)$, and five of them are actually subsequent strokes.

\subsection{Lightning Mapping of a Negative Sprite}

[39] Here we present the analysis of another negative sprite for which the associated lightning stroke was sufficiently close to the Oklahoma LMA that we can get additional information regarding the spatial development of the parent flash. This negative sprite, also reported by [Lyons, 2011], was observed at 06:49 UT on 9 September 2010 from Hawley, Texas. About half an hour later, the same storm produced two negative gigantic jets six minutes apart that emanated from the cloud top and progressed upward to the lower ionosphere [Lu et al., 2011c]. The lightning flash associated with this sprite produced multiple fast discharges detected by NLDN, including the major sprite-producing negative stroke with a peak current of $-129 \mathrm{kA}$. Magnetic fields recorded at $\sim 1500 \mathrm{~km}$ range near Duke University indicate that this stroke caused an exceptional iCMC well above $-500 \mathrm{C} \mathrm{km}$, clearly dominating over other NLDN discharges (Figure 14b). Some of the subsidiary discharges are subject to a questionable classification in type and/or polarity, as suggested by magnetic fields in the $50 \mathrm{~Hz}$ to $\sim 30 \mathrm{kHz}$ frequency range (Figure 14c) that are also recorded in Duke Forest. For example, the first NLDN discharge ( $\sim 6 \mathrm{~ms}$ prior to the sprite-producing negative stroke), as classified in error as a positive CG stroke with a peak current of $+21 \mathrm{kA}$, was clearly associated with a burst of very low frequency (VLF, 3-30 kHz) impulses. Similar VLF bursts are signatures of the preliminary breakdown linked to negative stepped leaders that encounter positive charge distributions at the bottom of the cloud on their way toward ground [Beasley et al., 1982; Nag and Rakov, 2009].

[40] At a distance of $\sim 260 \mathrm{~km}$ from the center of the Oklahoma LMA, the VHF observations of the spriteproducing flash are subject to considerable uncertainty in altitude and radial distance [Thomas et al., 2004; Lang et al., 2010]. Here we examine the spatial development of this flash on the basis of about 100 LMA sources located with reduced chi-square values $\leq 1.0$ using the detections by at least seven VHF receivers. Most of the LMA sources located at $260 \mathrm{~km}$ range should have originated from negative leaders that passed mainly through positively charged regions of the cloud [Thomas et al., 2001]. The temporal variation of these sources in altitude indicates that this flash progressed 

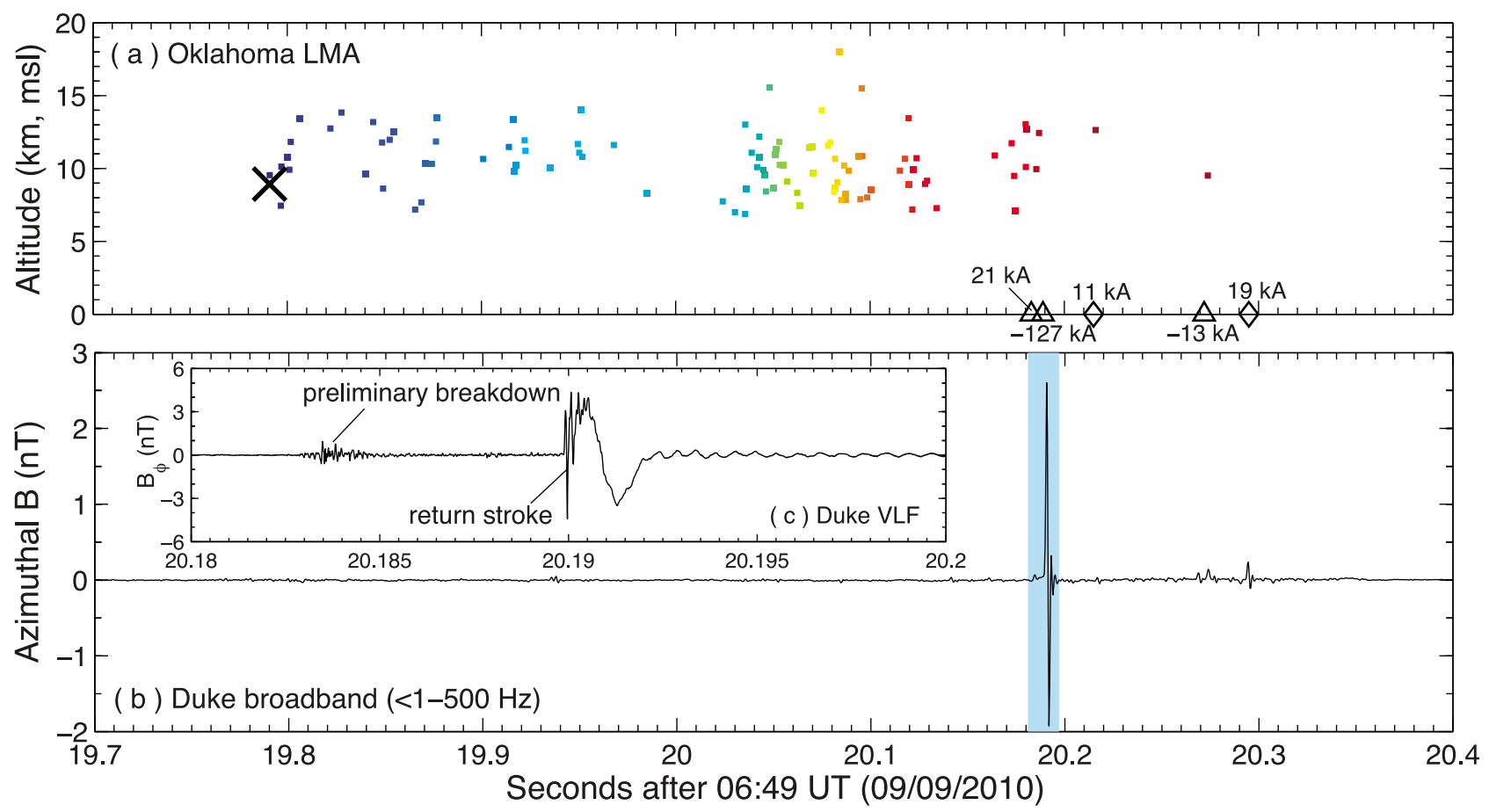

Figure 14. (a) Temporal variation in the altitude of VHF sources (color-coded by time) detected by the Oklahoma LMA for the parent flash of a sprite-producing negative stroke with a peak current of $-127 \mathrm{kA}$. NLDN detected this stroke and several other fast discharges (indicated by triangles for CG and diamonds for IC using NLDN classification) in the same flash. The flash origin is marked by a cross. (b) Broadband magnetic fields measured in Duke Forest showing the dominance of the sprite-producing negative stroke in impulse charge transfer over other discharges. (c) Magnetic fields in $50 \mathrm{~Hz}$ to $\sim 30 \mathrm{kHz}$ suggest that the sprite-producing negative stroke was preceded by preliminary breakdown likely associated with negative leader propagation through a lower positive charge region.

mainly in the upper part of the storm (Figure 14a). The flash began with a negative leader that initiated at $\sim 9 \mathrm{~km}$ altitude (as indicated by the first LMA point marked with a cross) and ascended to about $14 \mathrm{~km}$ (msl), presumably as the initial development of positive IC lightning. The sprite-producing negative stroke occurred $400 \mathrm{~ms}$ after the flash onset. There is no discernible VHF radiation indicative of a downward propagating negative leader prior to this negative stroke, making it difficult to associate the sprite-producing negative stroke with hybrid IC-NCG or bolt-from-the-blue lightning. However, as the NLDN location of the sprite-producing negative stroke was within $4 \mathrm{~km}$ laterally of the flash origin (and thus underneath the convective region [Lyons, 2011]), and the stroke was probably preceded by some preliminary breakdown, it is likely that this stroke has been produced in a hybrid IC-NCG flash. The bursts of VLF impulses are also observed to precede (by 5 to $8 \mathrm{~ms}$ ) all the three sprite-producing negative strokes discussed in section 5.1. Investigations of our cases with continuous VLF data available indicate that such characteristic signals are common to hybrid IC-NCG flashes but are not typical of bolt-from-theblue lightning.

[41] Therefore, the observations in Figure 14 provide evidence that the negative sprite is triggered by a negative stroke preceded by a significant leader progression in the upper part of the cloud as observed in positive IC lightning. This complies with our suggestion that negative sprite-producing strokes are produced in hybrid IC-NCG or bolt-from- the-blue lightning. The particular case reported here and probably all the three negative sprites observed from Duke Forest are most likely linked to hybrid IC-NCG. However, because the data sample is not large enough for this correlation to be regarded as conclusive, more observations of negative sprites or negative strokes capable of producing sprites near lightning mapping networks are needed to determine whether hybrid IC-NCG is the exclusive lightning type in favor of negative sprites. Nevertheless, bolt-fromthe-blue strokes with high peak currents remain one of the major producers of large negative iCMCs.

\section{Magnetic Field of Negative Leaders}

[42] To gain further insight into hybrid IC-NCG and boltfrom-the-blue flashes as two unusual lightning types that are the major sources of large iCMCs, we also investigated the electrical properties of the leader process prior to high peak current strokes associated with these lightning morphologies. Because of the background noise at the measuring site, our magnetic field data are not viable in most cases to assess stepped leader currents that are typically 100 to $200 \mathrm{~A}$ for negative strokes (in Florida thunderstorms) [Rakov and Uman, 2003]. However, a statistical analysis remains possible with the measurements for a sufficiently large number of strokes that are almost at equal distances from the magnetic sensor. Figure 15 shows the average magnetic field for four types of negative strokes with high peak currents, i.e., 


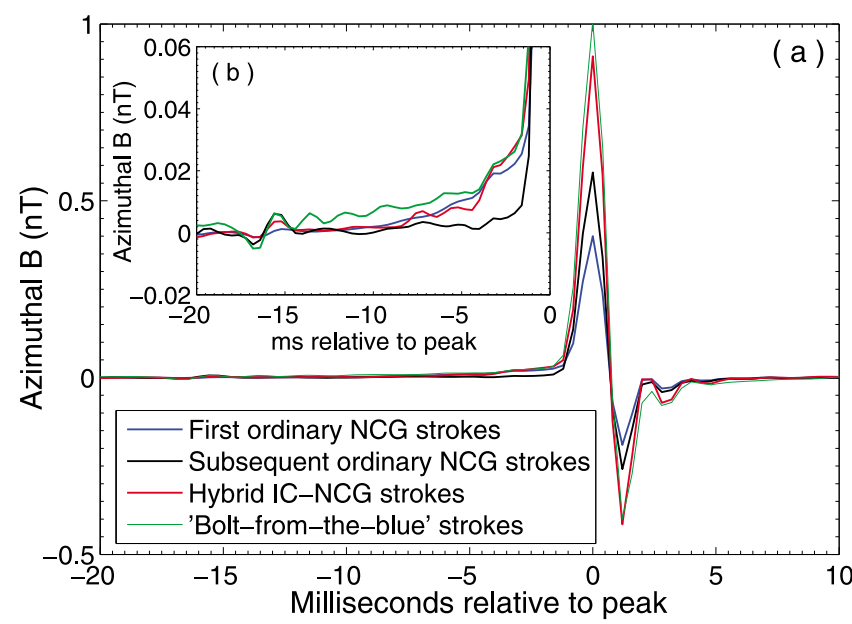

Figure 15. (a) Average magnetic fields of first and subsequent strokes in ordinary negative CG lightning, strokes in hybrid IC-NCG lightning, and bolt-from-the-blue strokes with peak currents higher than $-80 \mathrm{kA}$. (b) The slow magnetic field deflection caused by the downward propagation of negative leaders.

first and subsequent strokes in ordinary negative $\mathrm{CG}$, strokes in hybrid IC-NCG, and bolt-from-the-blue strokes. (The average magnetic field for first and subsequent strokes in hybrid NCC-IC is almost identical to that for ordinary negative CG lightning, and thus is not plotted here.) For each type of stroke, we first line up the associated slow magnetic pulses at the peak and sum the waveforms, which sum is then divided by the number of strokes to yield the average magnetic field as plotted in Figure 15a. Figure 15b expands the average magnetic waveforms to show the deflection caused by the downward negative leader prior to the return stroke.

[43] Several inferences can be drawn from Figure 15. The average magnetic fields for different types of negative strokes with high peak currents are similar in waveform, which suggests that impulse charge transfer in these strokes probably does not vary considerably in time scale. The relative magnitude of average magnetic fields is also consistent with aforementioned differences in the mean iCMCs. For example, high peak current subsequent strokes in ordinary negative CG flashes typically produce larger (by $\sim 40 \%$ ) iCMCs than first strokes with comparable peak currents. In addition, as shown in Figure 15b, the leader-associated magnetic field variation is not clear for subsequent strokes, which indicates that high peak current ordinary subsequent strokes are typically preceded by dart (or dart-stepped) leaders. Previous studies indicate that the duration of leader progression prior to return strokes is typically less than $2 \mathrm{~ms}$ [Rakov and Uman, 2003].

[44] Note that the average leader-associated magnetic field is almost the same for ordinary first strokes and hybrid ICNCG strokes, although these two stroke types differ by a factor of $\sim 2$ in the average iCMC magnitude. This suggests that the negative leaders prior to hybrid IC-NCG strokes do not necessarily carry higher current moments than negative leaders of ordinary first strokes. Bolt-from-the-blue strokes do not tend to correlate with particularly strong negative leaders either. However, the duration of leader-associated slow magnetic deflection is considerably longer than other stroke types. This is consistent with the fact that bolt-fromthe-blue leaders start to propagate downward from the altitude of the upper positive cloud region.

\section{Summary and Conclusions}

[45] We have investigated the relationship between lightning morphology and impulse charge transfer of high peak current negative strokes within optimum detection range of the north Alabama lightning mapping array. For each of the 2126 strokes detected by NLDN with peak currents over $-80 \mathrm{kA}$, the temporal and spatial development of parent lightning is examined by means of VHF mapping observations and the associated impulse charge moment change is estimated from broadband magnetic fields measured at $\sim 750 \mathrm{~km}$ range near Duke University. Impulse charge moment changes of these strokes exhibit a lognormal distribution with a long tail that approaches the critical values for driving red sprites in the mesosphere. Our analyses suggest that the impulse charge moment varies widely for specific (and relatively high) peak current, and lightning morphology strongly influences the impulse charge transfer of lightning strokes. The primary findings are as follows.

[46] 1. High peak current negative strokes can occur in association with four different lightning morphologies in north Alabama. The vast majority $(\sim 87 \%)$ occur as first or subsequent strokes in ordinary negative CG lightning and a close variant called hybrid NCG-IC that develops a distinct poststroke upper level negative leader progression as usually observed in positive IC flashes. High peak current strokes in these two lightning types rarely produce impulse charge moment changes (iCMCs) in excess of $-200 \mathrm{C} \mathrm{km}$ (in north Alabama). Instead, most of the largest iCMCs greater than $-200 \mathrm{C} \mathrm{km}$ are linked to hybrid IC-NCG lightning, which initially evolves as positive IC lightning and $K$ processes in the main negative region continue to produce negative ground strokes when the upper level negative leader ceases propagating. Some of the largest iCMCs are produced by bolt-from-the-blue strokes that result from an upper level negative leader that swerves downward to ground. In summary, the long tail present in the iCMC histogram for high peak current negative strokes is almost exclusively related to hybrid IC-NCG and bolt-from-the-blue lightning.

[47] 2. The four lightning morphologies associated with high peak current negative strokes also differ in the typical multiplicity. Ordinary negative CG lightning usually comprises four or more discrete ground strokes. In contrast, both hybrid NCG-IC and hybrid IC-NCG lightning tend to produce fewer strokes than ordinary negative CG lightning, probably because in both types part of the excessive charge in the midlevel negative cloud region is transported into the upper positive region of the cloud. The lightning-induced negative charge deposition in the lower positive charge region might play an important role in the formation of hybrid NCG-IC lightning [Qie et al., 2005a]. In hybrid ICNCG lightning, the lower positive charge center might participate in the production of negative strokes when the negative leaders activated by $K$ processes are forced to propagate toward ground.

[48] 3. The averaged magnetic field waveform provides information about the leader process prior to high peak 
current strokes in each lightning type on a statistical basis. This method is validated by showing that subsequent strokes in ordinary negative CG lightning are typically preceded by a dart leader of shorter duration than a stepped leader. Although hybrid IC-NCG strokes typically produce an impulse charge moment twice that of first ordinary negative strokes, the preceding stepped leaders do not carry higher change moments than those in ordinary negative CG flashes. The stepped leaders associated with bolt-from-the-blue strokes are not noticeably different either except for longer duration of downward progression, which though is not unexpected as they usually start at higher altitudes than stepped leaders in ordinary negative CG lightning.

[49] The above findings suggest that the potential of a negative stroke to produce a large iCMC capable of triggering sprites in the mesosphere is strongly dependent on the associated lightning morphology. In light of the statistical iCMC distributions for high peak current negative strokes with various morphologies (Figure 3), ordinary negative $\mathrm{CG}$ and hybrid NCG-IC lightning are least likely to produce sprites. Hybrid IC-NCG and bolt-from-the-blue lightning, both containing upper level negative leader progression prior to the CG stroke(s), are the two lightning types that are most conducive to negative sprites. This assertion is supported by the similarity between the multiplicity or stroke sequence of these two types and negative sprite-producing lightning. For example, the parent flashes of three negative sprites observed from Duke Forest produced one single stroke or a first stroke with dominance over other strokes, similar to the major stroke in hybrid IC-NCG and bolt-from-the-blue lightning. In addition, the parent flash of a negative sprite at $\sim 260 \mathrm{~km}$ range from the Oklahoma LMA progressed in the upper part of the cloud before spawning a sprite-producing CG stroke. The burst of VLF impulses preceding all of these negative sprite-producing ground strokes provides additional clues that hybrid IC-NCG flashes might be the major lightning type associated with negative sprites.

[50] This work demonstrates the usefulness of combining VHF mapping observations of lightning flashes and remote sensing of broadband magnetic fields to study lightning charge transfer. Note that the results presented here pertain to lightning strokes in a10,000 $\mathrm{km}^{2}$ area within the ideal coverage of the north Alabama LMA. Since February of 2011, a low light level video system has been installed on the campus of University of Mississippi to monitor lightning-associated transient luminous phenomena over north Alabama. There have been numerous observations of sprites related to positive ground strokes, but no negative sprite has yet been documented. It is also worthwhile to extend the survey to other regional lightning mapping networks, including the Four-Dimensional Lightning Surveillance System (4DLSS) at the NASA/Kennedy Space Center that provides observations of lightning flashes near the east coast of Florida [Roeder, 2010]. Although it is not clear how a different surface condition (land/sea) would influence the impulse charge transfer in lightning strokes, observations suggested that negative strokes with exceptionally large charge moment changes are probably more frequent in coastal/oceanic regions [Füllekrug et al., 2002]. Also, in any case, ordinary negative $\mathrm{CG}$ strokes may produce sprites under favorable conditions, such as elevated negative charge regions possessed by thunderstorms with an inverted- polarity electrical structure [Rust et al., 2005]. It is therefore necessary to investigate the impulse charge transfer of high peak current negative strokes in a variety of geographic areas and thunderstorm conditions.

[51] Acknowledgments. This work was supported by the Physical and Dynamic Meteorology Program of the National Science Foundation and the NIMBUS Program of the Defense Advanced Research Projects Agency. Lucian Zigoneanu is acknowledged for routinely operating the low light level video camera in Duke Forest.

\section{References}

Barrington-Leigh, C. P., U. S. Inan, M. Stanley, and S. A. Cummer (1999), Sprites triggered by negative lightning discharges, Geophys. Res. Lett., 26, 3601-3608.

Beasley, W., M. A. Uman, and P. L. Rustan Jr. (1982), Electric fields preceding cloud-to-ground lightning flashes, J. Geophys. Res., 87, 4883-4902.

Boccippio, D. J., E. R. Williams, S. J. Heckman, W. A. Lyons, I. T. Baker, and R. Boldi (1995), Sprites, ELF transients and positive ground strokes, Science, 269, 1088-1091.

Brook, M., N. Kitagawa, and E. J. Workman (1962), Quantitative study of strokes and continuing currents in lightning discharges to ground, J. Geophys. Res., 67, 649-659.

Clarence, N. D., and D. J. Malan (1957), Preliminary discharge processes in lightning flashes to ground, Q. J. R. Meteorol. Res., 83, 161-172.

Coleman, L. M., T. C. Marshall, M. Stolzenburg, T. Hamlin, P. R. Krehbiel, W. Rison, and R. J. Thomas (2003), Effects of charge and electrostatic potential on lightning propagation, J. Geophys. Res., 108(D9), 4298, doi:10.1029/2002JD002718.

Coleman, L. M., M. Stolzenburg, T. C. Marshall, and M. Stanley (2008), Horizontal lightning propagation, preliminary breakdown, and electric potential in New Mexico thunderstorms, J. Geophys. Res., 113, D09208, doi:10.1029/2007JD009459.

Cummer, S. A. (2003), Current moment in sprite-producing lightning, J. Atmos. Sol. Terr. Phys., 65, 499-508.

Cummer, S. A., and U. S. Inan (2000), Modeling ELF radio atmospheric propagation and extracting lightning currents from ELF observations, Radio Sci., 35(2), 385-394.

Cummer, S. A., and W. A. Lyons (2004), Lightning charge moment changes in U.S. high plains thunderstorms, Geophys. Res. Lett., 31, L05114, doi:10.1029/2003GL019043.

Cummer, S. A., and W. A. Lyons (2005), Implications of lightning charge moment changes for sprite initiation, J. Geophys. Res., 110, A04304, doi:10.1029/2004JA010812.

Cummins, K. L., and M. J. Murphy (2009), An overview of lightning location systems: History, techniques, and data uses, with an in-depth look at the U.S. NLDN, IEEE Trans. Electromagn. Compat., 51(3), 499-518.

Füllekrug, M., C. Price, Y. Yair, and E. R. Williams (2002), Intense oceanic lightning, Ann. Geophys., 20, 133-137.

Goodman, S. J., et al. (2005), The north Alabama lightning mapping array: Recent severe storm observations and future prospects, Atmos. Res., 76, 423-437, doi:10.1016/j.atmosres.2004.11.035.

Hager, W. W., R. G. Sonnenfeld, B. C. Aslan, J. Battles, G. Lu, W. P. Winn, and W. L. Boeck (2007), Analysis of charge transport during lightning using balloon-borne electric field sensors and lightning mapping array, J. Geophys. Res., 112, D18204, doi:10.1029/2006JD008187.

$\mathrm{Hu}, \mathrm{W}$. , and S. A. Cummer (2006), An FDTD model for low and high altitude lightning-generated EM fields, IEEE Trans. Antennas Propag., 54(5), 1513-1522.

$\mathrm{Hu}$, W., S. A. Cummer, W. A. Lyons, and T. E. Nelson (2002), Lightning charge moment changes for the initiation of sprites, Geophys. Res. Lett. 29(8), 1279, doi:10.1029/2001GL014593.

Kasemir, H. W. (1960), A contribution to the electrostatic theory of a lightning discharge, J. Geophys. Res., 65, 1873-1878.

Krehbiel, P. R. (1981), An analysis of the electric field change produced by lightning, $\mathrm{PhD}$ dissertation, Univ. of Manchester Inst. of Sci. and Technol., Manchester, U. K.

Krehbiel, P. R., M. Brook, and R. A. McCrory (1979), An analysis of the charge structure of lightning discharges to ground, J. Geophys. Res., 84, 2432-2456.

Krehbiel, P. R., J. A. Riousset, V. P. Pasko, R. J. Thomas, W. Rison, M. A Stanley, and H. E. Edens (2008), Upward electrical discharges from thunderstorms, Nat. Geosci., 1, 233-237.

Lang, T. J., W. A. Lyons, S. A. Rutledge, J. D. Meyer, D. R. MacGorman, and S. A. Cummer (2010), Transient luminous events above two mesoscale convective systems: Storm structure and evolution, J. Geophys. Res., 115, A00E22, doi:10.1029/2009JA014500. 
Liu, X., and P. R. Krehbiel (1985), The initial streamer of intracloud lightning flashes, J. Geophys. Res., 90, 6211-6218.

Lu, G., S. A. Cummer, J. Li, F. Han, R. J. Blakeslee, and H. J. Christian (2009), Charge transfer and in-cloud structure of large-charge-moment positive lightning strokes in a mesoscale convective system, Geophys. Res. Lett., 36, L15805, doi:10.1029/2009GL038880.

Lu, G., et al. (2010), Lightning mapping observation of a terrestrial gammaray flash, Geophys. Res. Lett., 37, L11806, doi:10.1029/2010GL043494.

Lu, G., S. A. Cummer, J. Li, F. Han, D. M. Smith, and B. W. Grefenstette (2011a), Characteristics of broadband lightning emissions associated with terrestrial gamma ray flashes, J. Geophys. Res., 116, A03316, doi:10.1029/2010JA016141.

Lu, G., W. P. Winn, and R. G. Sonnenfeld (2011b), Charge transfer during intracloud lightning from a time-dependent multi-dipole model, J. Geophys. Res., 116, D03209, doi:10.1029/2010JD014495.

Lu, G., et al. (2011c), Lightning development associated with two negative gigantic jets, Geophys. Res. Lett., 38, L12801, doi:10.1029/ $2011 \mathrm{GL} 047662$

Lyons, W. A. (1996), Sprite observations above the U.S. high plains in relation to their parent thunderstorm systems, J. Geophys. Res., 101, $29,641-29,652$.

Lyons, W. A. (2011), TLEs and their parent lightning discharges, paper presented at XIV International Conference on Atmospheric Electricity, Int Comm. on Atmos. Electr., Rio de Janeiro, Brazil, 08-12 Aug.

Maggio, C. R., T. Marshall, and M. Stolzenburg (2009), Estimations of charge transferred and energy released by lightning flashes, J. Geophys. Res., 114, D14203, doi:10.1029/2008JD011506.

Mazur, V. (2002), Physical processes during development of lightning flashes, C. R. Phys., 3, 1393-1409.

Nag, A., and V. A. Rakov (2009), Some inferences on the role of lower positive charge region in facilitating different types of lightning, Geophys. Res. Lett., 36, L05815, doi:10.1029/2008GL036783.

Pasko, V. P., U. S. Inan, T. F. Bell, and Y. N. Taranenko (1997), Sprites produced by quasi-electrostatic heating and ionization in the lower ionosphere, J. Geophys. Res., 102, 4529-4561.

Pawar, S. D., and A. K. Kamra (2004), Evolution of lightning and the possible initiation/triggering of lightning discharges by the lower positive charge center in an isolated thundercloud in the tropics, J. Geophys. Res., 109, D02205, doi:10.1029/2003JD003735.

Proctor, D. E. (1997), Lightning flashes with high origins, J. Geophys. Res., 102, 1693-1706.

Qie, X., X. Kong, G. Zhang, T. Zhang, T. Yuan, Y. Zhou, Y. Zhang, H. Wang, and A. Sun (2005a), The possible charge structure of thunderstorm and lightning discharges in northeastern verge of Qinghai-Tibetan Plateau, Atmos. Res., 76, 231-246.

Qie, X., T. Zhang, C. Chen, G. Zhang, T. Zhang, and W. Wei (2005b), The lower positive charge center and its effect on lightning discharges on the Tibetan Plateau, Geophys. Res. Lett., 32, L05814, doi:10.1029/ 2004GL022162.

Rachidi, F., J. L. Bermudez, M. Rubinstein, and V. A. Rakov (2004), On the estimation of lightning peak currents from measured fields using lightning location systems, J. Electrost., 60, 121-129.

Rakov, V. A., and M. A. Uman (1990), Some properties of negative cloudto-ground lightning flashes versus stroke order, J. Geophys. Res., 95, $5447-5453$.

Rakov, V. A., and M. A. Uman (2003), Lightning: Physics and Effects, Cambridge Univ. Press, New York.

Riousset, J. A., V. P. Pasko, P. R. Krehbiel, W. Rison, and M. A. Stanley (2010), Modeling of thundercloud screening charges: Implications for blue and gigantic jets, J. Geophys. Res., 115, A00E10, doi:10.1029/ 2009JA014286.

Rison, W., R. J. Thomas, P. R. Krehbiel, T. Hamlin, and J. Harlin (1999), A GPS-based three-dimensional lightning mapping system: Initial observations in central New Mexico, Geophys. Res. Lett., 26(23), 3573-3576.
Roeder, W. P. (2010), The four dimensional lightning surveillance system, paper presented at 21st International Lightning Detection Conference, Vaisala, Orlando, Fla.

Ross, M., S. A. Cummer, T. K. Nielsen, and Y. Zhang (2008), Simultaneous remote electric and magnetic field measurements of lightning continuing currents, J. Geophys. Res., 113, D20125, doi:10.1029/2008JD010294.

Rust, W. D., D. R. MacGorman, E. C. Bruning, S. A. Weiss, P. R. Krehbiel, R. J. Thomas, W. Rison, T. Hamlin, and J. Harlin (2005), Invertedpolarity electrical structure in thunderstorms in the Severe Thunderstorm Electrification and Precipitation Study (STEPS), Atmos. Res., 76, 247-271.

Schoene, J., M. A. Uman, and V. A. Rakov (2010), Return stroke peak current versus charge transfer in rocket-triggered lightning, J. Geophys. Res. 115, D12107, doi:10.1029/2009JD013066.

Shao, X.-M., and P. R. Krehbiel (1996), The spatial and temporal development of intracloud lightning, J. Geophys. Res., 101, 26,641-26,668.

Shao, X.-M., P. R. Krehbiel, R. J. Thomas, and W. Rison (1995), Radio interferometric observations of cloud-to-ground lightning phenomena in Florida, J. Geophys. Res., 100, 2749-2783.

Smith, D. A., et al. (2011), A terrestrial gamma ray flash observed from an aircraft, J. Geophys. Res., 116, D20124, doi:10.1029/2011JD016252.

Sonnenfeld, R. G., J. D. Battles, G. Lu, and W. P. Winn (2006), Comparing $E$ field changes aloft to lightning mapping data, J. Geophys. Res., 111, D20209, doi:10.1029/2006JD007242.

Taylor, M. J., et al. (2008), Rare measurements of a sprite with halo event driven by a negative lightning discharge over Argentina, Geophys. Res. Lett., 35, L14812, doi:10.1029/2008GL033984.

Thomas, R. J., P. R. Krehbiel, W. Rison, T. Hamlin, J. Harlin, and D. Shown (2001), Observations of VHF source powers radiated by lightning, Geophys. Res. Lett., 28, 143-146, doi:10.1029/2000GL011464.

Thomas, R. J., P. R. Krehbiel, W. Rison, S. J. Hunyady, W. P. Winn, T. Hamlin, and J. Harlin (2004), Accuracy of the lightning mapping array, J. Geophys. Res., 109, D14207, doi:10.1029/2004JD004549.

Thomson, E. M., M. A. Uman, and W. H. Beasley (1985), Speed and current for lightning stepped leaders near ground as determined from electric field records, J. Geophys. Res., 90, 8136-8142.

Warner, T. A., J. H. Helsdon Jr., and A. G. Detwiler (2003), Aircraft observations of a lightning channel in steps, Geophys. Res. Lett., 30(19), 1984, doi:10.1029/2003GL017334.

Willett, J. C., J. C. Bailey, V. P. Idone, A. Eybert-Berard, and L. Barret (1989), Submicrosecond intercomparison of radiation fields and currents in triggered lightning return strokes based on the transmission-line model, J. Geophys. Res., 94, 13,275-13,286.

Williams, E. R. (1989), The tripole structure of thunderstorms, J. Geophys. Res., 94, 13,151-13,167.

Williams, E., E. Downes, R. Boldi, W. Lyons, and S. Heckman (2007), Polarity asymmetry of sprite-producing lightning: A paradox?, Radio Sci., 42, RS2S17, doi:10.1029/2006RS003488.

Winn, W. P., G. D. Aulich, S. J. Hunyady, K. B. Eack, H. E. Edens, P. R Krehbiel, W. Rison, and R. G. Sonnenfeld (2011), Lightning leader stepping, $\mathrm{K}$ changes, and other observations near an intracloud flash, J. Geophys. Res., 116, D23115, doi:10.1029/2011JD015998.

W. H. Beasley and S. Weiss, School of Meteorology, University of Oklahoma, Sarkeys Energy Center, 100 E. Boyd St., Norman, OK 73019 , USA. (whb@ou.edu; stepha.weiss@gmail.com)

R. J. Blakeslee, Earth Science Office, NASA Marshall Space Flight Center, 320 Sparkman Dr., Huntsville, AL 35805, USA. (rich.blakeslee@nasa.gov)

S. A. Cummer and G. Lu, Department of Electrical and Computer Engineering, Duke University, Box 90291, Hudson Hall 05C, Durham, NC 27708, USA. (cummer@ee.duke.edu; gaopeng.lu@duke.edu) 